\title{
DENSIDADE DO SOLO: INFLUÊNCIA DA POSIÇÃO RELATIVA À LINHA DE PLANTIO EM DOIS SISTEMAS DE PREPARO DO SOLO
}

\section{VLADIA CORRECHEL}

Engenheira Agrônoma

Orientador: Prof. Dr. ALVARO PIRES DA SILVA

Dissertação apresentada à Escola Superior de Agricultura "Luiz de Queiroz", Universidade de São Paulo, para obtenção do título de Mestre e Agronomia, Área de Concentração: Solos e Nutrição de Plantas.

PIRACICABA

Estado de São Paulo - Brasil

Janeiro - 1998 
Dados Internacionais de Catalogação na Publicação (CIP)

DIVISÃo DE BIBLIOTECA E DOCUMENTAÇÃO - Campus "Luiz de Queiroz"/USP

Correchel, Vladia

Densidade do solo : influência da posição relativa à linha de plantio em dois sistemas de preparo do solo / Vladia Correchel. - Piracicaba, 1998.

$41 \mathrm{p}$.

Dissertação (mestrado) - - Escola Superior de Agricultura Luiz de Queiroz, 1998.

Bibliografia.

1. Latossolo roxo 2. Parâmetro físico 3. Preparo do solo I. Titulo

CDD 631.51

631.43 


\section{DENSIDADE DO SOLO: INFLUÊNCIA DA POSIÇÃO RELATIVA À LINHA DE PLANTIO EM DOIS SISTEMAS DE PREPARO DO SOLO}

VLADIA CORRECHEL

Aprovada em: 18.02 .1998

Comissão julgadora:

Alvaro Pires da Silva

ESALQ/USP

Paulo Leonel Libardi ESALQ/USP

Isabella C. de Maria

SCS/IAC

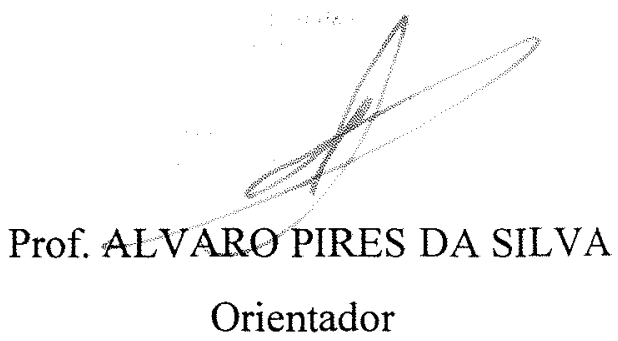


Ao meu esposo, aos meus pais, irmão e familiares dedico o presente trabalho 
Agradeço a todos que de alguma forma contribuíram para a realização desse trabalho. Em especial expresso minha gratidão às seguintes pessoas:

Ao Prof. Dr. Alvaro Pires da Silva pelo incentivo e orientação na execução do trabalho;

Aos Prof. Dr. Francisco Antônio Monteiro e Quirino A. de C. Carmello pelo apoio e confiança oferecidos;

Ao Prof. Dr. Paulo Leonel Libardi e à Dra. Isabella C. de Maria pelas valiosas sugestões;

Ao Conselho Nacional de Pesquisa (CNPq) pelo apoio financeiro;

Aos proprietários da Fazenda Cachoeirinha (Guaira, SP) que gentilmente cederam a propriedade para a realização desta pesquisa;

Aos colegas Andrea C. Sanchez, Cassio A. Tormena e Silvia Imnhoff pelo auxilio na condução do experimento, estímulo e amizade;

Aos funcionários do Departamento de Ciência do Solo da ESALQ/USP pela ajuda quando necessária. 
SUMÁRIO

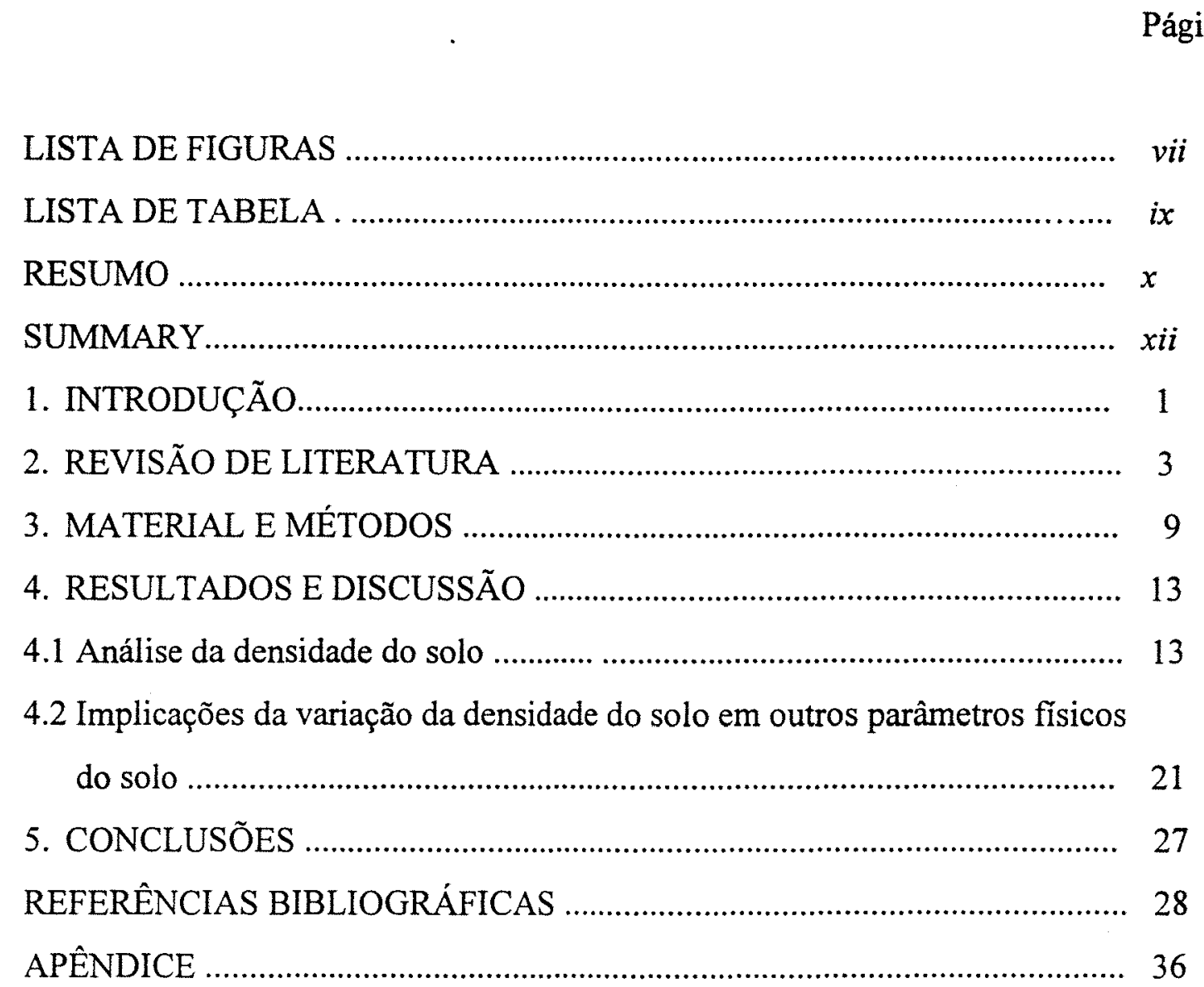




\section{LISTA DE FIGURAS}

Figura $n^{0}$

Página

1 Esquema de coleta das amostras com estrutura indeformada em um latossolo roxo no município de Guaíra, SP, ao longo de uma transeção perpendicular às linhas de plantio, nas posições linha e entrelinha .........

2 Densidade do solo $\left(\mathrm{Mg} \mathrm{m}^{-3}\right)$ nos sistemas de preparo convencional (PC) e plantio direto (PD)

3 Densidade do solo $\left(\mathrm{Mg} \mathrm{m}^{-3}\right)$ na posição linha nos sistemas de preparo convencional (PC) e plantio direto (PD)

4 Densidade do solo $\left(\mathrm{Mg} \mathrm{m}^{-3}\right)$ na posição entrelinha nos sistemas de preparo convencional (PC) e plantio direto (PD)

5 Efeito da posição relativa à linha de plantio na densidade do solo $\left(\mathrm{Mg} \mathrm{m}^{-3}\right)$ no sistema de plantio direto em um latossolo roxo localizado no município de Guaíra, SP., nas posições linha (L) e entrelinha (EL)..

6 Efeito da posição relativa à linha de plantio na densidade do solo $\left(\mathrm{Mg} \mathrm{m}^{-3}\right)$ no sistema de preparo convencional em um latossolo roxo localizado no município de Guaíra, SP., nas posições linha (L) e entrelinha (EL)

7 Densidade do solo $\left(\mathrm{Mg} \mathrm{m}^{-3}\right)$ ao longo da transeção de amostragem no sistema de plantio direto (PD) e preparo convencional (PC)

8 Densidade espectral $\left(\left(\mathrm{Mg} \mathrm{m}^{-3}\right)^{2}\right)$ da densidade do solo nos sistemas de plantio direto (PD) e preparo convencional (PC)

9 Porosidade de aeração ( $\mathrm{P}_{\mathrm{ar}}, \%$ ) na posição linha (L) e entrelinha (EL) no sistema de plantio direto ao longo de uma seqüência de amostragem perpendicular às linhas de plantio em um latossolo roxo cultivado com milho para umidade do solo equivalente a tensão de $0,033 \mathrm{MPa} . . \quad 22$

10 Porosidade de aeração $\left(\mathrm{P}_{\mathrm{ar}}, \%\right)$ na posição linha (L) e entrelinha (EL) no sistema de preparo convencional ao longo de uma sequiência de amostragem perpendicular às linhas de plantio em um latossolo roxo cultivado com milho para umidade do solo equivalente a tensão de $0,033 \mathrm{MPa}$ 
11 Resistência do solo à penetração (RP) na posição linha (L) e entrelinha (EL) no sistema de plantio direto ao longo de uma seqüência de amostragem perpendicular às linhas de plantio em um latossolo roxo cultivado com milho para umidade do solo equivalente a tensão de 0,70

$\mathrm{MPa}$

12 Resistência do solo à penetração (RP) na posição linha (L) e entrelinha (EL) no sistema de preparo convencional ao longo de uma sequiência de amostragem perpendicular às linhas de plantio em um latossolo roxo cultivado com milho para umidade do solo equivalente a tensão de $0,70 \mathrm{MPa}$ 


\section{LISTA DE TABELA}

Tabela $\mathrm{n}^{\circ}$

Página

1 Parâmetros da análise estatística dos dados de densidade do solo para os dois sistemas de preparo do solo .......................... 13 


\section{DENSIDADE DO SOLO: INFLUÊNCIA DA POSIÇÃO RELATIVA À LINHA DE PLANTIO EM DOIS SISTEMAS DE PREPARO DO SOLO}

Vladia Correchel

Orientador: Prof. Dr. Alvaro Pires da Silva

\section{RESUMO}

A densidade do solo é um parâmetro físico de fácil obtenção e quantificação, relacionando-se com outras propriedades intrínsecas tais como a textura e a matéria orgânica. Vários parâmetros físicos do solo tais como a porosidade total, o intervalo hídrico ótimo, a resistência à penetração, a porosidade de aeração e o conteúdo de água disponível estão relacionados com a densidade do solo. Na comparação entre sistemas de preparo a densidade do solo tem sido uma das variáveis mais freqüentemente usadas mas pouco tem sido explorado o fato de que os sistemas de manejo do solo e das culturas podem introduzir grande variabilidade em seus valores no espaço. Os fatores que determinam esta variação são os tráfegos resultantes das operações de manejo, os processos de consolidação ou adensamento natural e os efeitos do sistema radicular das culturas. Durante o crescimento das culturas estes fatores tornam explícita a variação da densidade do solo em relação a linha de cultivo com a influência do sistema de preparo do solo. O objetivo deste trabalho foi avaliar a densidade do solo em dois sistemas de preparo para identificar se a densidade do solo é influenciada pela posição linha e entrelinha e se esta distribuição ocorre de forma sistemática. As amostragens foram feitas em um latossolo roxo sob plantio direto e convencional, em transeções perpendiculares às linhas da cultura de milho, permitindo obter amostras nas posições linha e entrelinha da cultura. Os efeitos dos sistemas de preparo e da posição de amostragem foram quantificados através do teste $\mathrm{t}$ e a influência do preparo e da posição 
sobre a variação sistemática da densidade do solo foi avaliada pela análise espectral através da série de Fourier. Os resultados permitiram concluir que a densidade do solo é influenciada pela posição de amostragem, independente do sistema de preparo do solo, e que a variação da densidade do solo ocorre de forma sistemática com a posição de amostragem. 


\title{
DENSITY OF SOIL: INFLUENCE OF RELATIVE POSITION TO THE CROP IN SOIL TWO TILLAGE SYSTEMS
}

\author{
Author: Vladia Correchel \\ Adviser: Prof. Dr. Alvaro Pires da Silva
}

\section{SUMMARY}

Bulk density is a soil physical parameter that can be measured in a routine basis and it is an useful parameter for quantifying soil compactness. Properties such as soil resistance, soil moisture, and the least limiting water range are strongly correlated with bulk density. Bulk density has also been extensively used to compare tillage treatments effects on soil structure. The objectives of this study were to: (i) evaluate the effects of tillage and position relative to the crop (row and interrow) on bulk density, and (ii) identify whether bulk density variation relative to the crop position is systematic. The experiment was carried out on an Oxisol under no-till (NT) and conventional tillage (CT) treatments. Ninety-four undisturbed samples were taken on a transect on both tillage treatments. $\underline{t}$ test and spectral analyses were used to analyze the bulk density data. There was a significant difference in bulk density (NT>CT) only at the row position. Bulk density was higher in the interrow position than in the row position on both tillage treatments. Spectral analyses indicated that the bulk density variation relative to the position was systematic. 


\section{INTRODUÇÃO}

Para quantificar o impacto das práticas de manejo do solo e das culturas na estrutura do solo, diversos parâmetros indicadores da qualidade do solo podem ser utilizados, entre os quais destaca-se a densidade do solo pela simplicidade e facilidade de obtenção e quantificação. As modificações na estrutura do solo pelas práticas de manejo influenciam a densidade do solo de forma que esta é freqüentemente utilizada na quantificação da compactação do solo.

O grau e a intensidade de mobilização do solo influenciam os valores de Ds como constatado em comparações de plantio direto com o preparo convencional do solo. No preparo convencional o solo é intensamente mobilizado resultando na incorporação de resíduos vegetais pela inversão da camada arável. Já no sistema de plantio direto, a mobilização do solo ocorre apenas na linha de semeadura, permanecendo os resíduos culturais sobre a superfície do solo.

Os efeitos do sistema de preparo do solo na variação da densidade do solo podem ser manifestados de forma diferenciada em função do tráfego e da posição relativa à linha de plantio. A hipótese de que a variação da densidade do solo é influenciada pela posição relativa à linha de plantio sendo este efeito sistemático e influenciado pelo sistema de preparo do solo, o presente estudo foi elaborado.

O objetivo geral do trabalho foi avaliar a distribuição da densidade do solo em dois sistemas de preparo em um latossolo roxo, cultivado com milho. Os objetivos específicos foram: (i) identificar o efeito da posição relativa à linha de cultivo na variação da densidade do solo; (ii) verificar se o efeito da posição relativa à linha de plantio na distribuição da densidade do solo depende do sistema de preparo do solo e 
(iii) avaliar se a variação da densidade do solo ocorre de forma sistemática com a posição relativa à linha de cultivo. 


\section{REVISÃO DE LITERATURA}

As práticas de manejo do solo e das culturas influenciam os atributos físicos do solo com impacto sobre a produtividade das culturas. Para quantificar a influência das práticas de manejo do solo e das culturas na sustentabilidade do agroecossistema, diversos parâmetros podem ser utilizados, entre os quais destaca-se a densidade do solo que é facilmente mensurável e incorpora aspectos da estrutura do solo que interferem diretamente em outras propriedades físicas do solo (Erbach, 1987; Silva et al., 1997).

Pedrotti (1995) cita algumas alterações originadas da compactação em solos agrícolas em parâmetros como o aumento da resistência do solo à penetração radicular, a redução da aeração, a alteração na disponibilidade e fluxo de água, calor e nutrientes.

A compactação do solo causada pelo tráfego de máquinas e implementos sobre a superfície principalmente quando o solo está úmido promove a elevação da densidade do solo com a ocorrência de efeitos indesejáveis tais como o atraso na emergência das plântulas e a diminuição do sistema radicular (Soane et al.,1981).

A variação da densidade do solo está relacionada com características intrínsecas do solo, notadamente a textura e a matéria orgânica. Bodman \& Constantin (1965) trabalhando com misturas de diferentes tamanhos de partículas ilustraram a influência da textura na densidade do solo. Observaram que os valores máximos de densidade do solo ocorreram em amostras que continham $75 \%$ ou mais de areia na composição da mistura, o que esta relacionado a diferentes densidades apresentadas pelas partículas do solo.

Jones (1983) também observou um decréscimo na densidade do solo com o aumento do teor de argila. Mairinque \& Jones (1991) utilizando dados de 12000 perfis de solo de diferentes países desenvolveram regressões múltiplas para estimar a densidade do solo a partir de propriedades do solo como a porcentagem de argila e o 
conteúdo de matéria orgânica. Para diminuir a variabilidade da densidade do solo, eles dividiram os perfis estudados em ordens e sub-ordens, de acordo com a classificação taxonômica. Observaram que a estimativa da densidade do solo variou com o conteúdo de matéria orgânica, com a textura do solo e com o tipo de solo, indicando que existem outros fatores que determinam o valor da densidade do solo.

O preparo do solo também influencia os valores de densidade do solo. Neste sentido muitos estudos utilizam a densidade do solo para comparar o plantio direto com o preparo convencional. No preparo convencional, os agregados do solo são fraturados (Dexter, 1979) devido a intensa mobilização do solo, resultando na incorporação de resíduos vegetais pela inversão da camada arável. Já no sistema de plantio direto, a mobilização do solo ocorre apenas na linha de semeadura, permanecendo os resíduos culturais sobre a superfície do solo.

Pidgeon \& Soane (1977) verificaram maiores valores da densidade do solo no sistema de plantio direto quando comparado ao sistema de preparo convencional. Gantzer \& Blake (1978) conduziram um experimento em solos de textura argilosa para comparar os efeitos do sistema de plantio direto e do preparo convencional em algumas propriedades físicas do solo e concluíram que, sob plantio direto, os solos argilosos na camada arável apresentaram diferenças significativas nas características físicas em relação ao preparo convencional. A densidade do solo foi significativamente maior no plantio direto do que no preparo convencional.

Também Machado \& Brum (1978), trabalhando com latossolos submetidos ao preparo convencional, plantio direto, mata nativa e campo nativo, constataram maior densidade do solo no preparo convencional comparativamente ao plantio direto, campo nativo e mata virgem na camada de 0-15 cm. Vieira \& Muzilli (1984) observaram que o plantio direto aumentou significativamente a densidade do solo em comparação ao preparo convencional, com conseqüente redução na porosidade total e na macroporosidade. Resultados semelhantes foram obtidos por Cintra et al. (1983) e Sidiras et al. (1984). 
Hill (1990) constatou que a maior densidade do solo no plantio direto em relação ao preparo convencional foi responsável pelo aumento da resistência do solo à penetração no plantio direto. Desta forma, através da densidade do solo, foi possível avaliar as alterações na estrutura dos solos pelo sistema de preparo do solo utilizado. Outros pesquisadores, porém, não obtiveram diferenças significativas da densidade do solo entre os sistemas de preparo convencional e plantio direto. Hill \& Cruse (1985) compararam os efeitos dos sistemas de preparo reduzido, preparo convencional e plantio direto sobre a densidade do solo em solos expostos à diferentes períodos de duração de cultivo, não observando variação significativa na densidade do solo.

Os resultados de um estudo realizado por Mielke et al. (1986), mostraram que as principais diferenças nas características físicas do solo entre os sistemas de preparo foram confinadas aos primeiros 7,5 cm de profundidade no solo. Scott \& Wood (1989) quantificaram o impacto da produção agrícola no ambiente físico do solo através de diversos parâmetros em solos cultivados por 1, 12 e 30 anos e em um solo virgem.

Observaram que, em geral, a densidade do solo aumentou em profundidade em todas as áreas estudadas. Nos solos cultivados por 1 ano a densidade do solo na profundidade de 0 a $5 \mathrm{~cm}$ foi significativamente menor do que em outras profundidades analisadas, enquanto no solo cultivado há 12 anos, não foi verificada diferença significativa na densidade do solo ao longo do perfil de solo.

Merten \& Mielniczuk (1991) não observaram diferenças significativas na densidade do solo, na macroporosidade e na microporosidade entre os sistemas de preparo do solo, estudando a distribuição do sistema radicular de quatro culturas em um latossolo roxo submetido ao plantio direto e ao preparo convencional. Já Kaspar et al. (1991) examinando o efeito do sistema de preparo na distribuição das raízes de milho observaram que o aumento na densidade do solo, causada pelo tráfego das máquinas, alterou a distribuição do sistema radicular independente do sistema de preparo.

Estudando os efeitos de sistemas de rotação de culturas e de sistemas de preparo do solo na estrutura do solo Albuquerque et al. (1995) também não observaram 
diferenças significativas na densidade do solo e em outros atributos físicos do solo entre os sistemas de plantio direto e preparo convencional.

A diferença nos resultados encontrados na literatura entre o plantio direto e o preparo convencional pode estar relacionada a época, à posição e a profundidade de amostragem e ao tempo de implantação do sistema de plantio direto. Os efeitos do sistema de preparo do solo na variação da densidade do solo podem ser manifestados de forma diferenciada de acordo com a posição relativa à linha de plantio.

Cassel (1982) ilustra a magnitude das variações da densidade do solo impostas pelas operações de preparo do solo enfatizando a importância da posição relativa à linha de plantio na distribuição da densidade do solo. Kaspar et al. (1995) não observaram diferenças significativas da densidade do solo em entrelinhas trafegadas e não trafegadas da cultura do milho, demonstrando a influência do sistema de preparo na variação da densidade do solo para profundidade de 3,8 a $11,4 \mathrm{~cm}$.

Os efeitos do tráfego em um dos lados das linhas de milho e de soja em duas profundidades foram estudados por Fausey \& Dylla (1984). Os autores observaram que a densidade do solo foi significativamente maior na profundidade de 0 a $0,15 \mathrm{~m}$ e de 0,15 a 0,30 m nas áreas trafegadas em comparação com as áreas não trafegadas.

Outros estudos neste sentido foram desenvolvidos por Bauder et al. (1985) para verificar os efeitos do sistema de preparo do solo e do tráfego de rodas nas entrelinhas das culturas sobre algumas propriedades do solo e no crescimento radicular de milho. Verificaram que a densidade do solo no plantio direto foi significativamente maior na entrelinha trafegada comparativamente à não trafegada. A resistência do solo à penetração apresentou um efeito significativo na posição intermediária entre a linha da cultura e a entrelinha trafegada na profundidade de 0 a $0,75 \mathrm{~m}$, reduzindo o comprimento total de raízes e a densidade do comprimento de raízes na posição entrelinha.

Gerik et al. (1987) observaram que a resistência do solo à penetração e a densidade do solo não diferiram significativamente entre dois sistemas de preparo em áreas não trafegadas, mas foram maiores nas áreas trafegadas no solo sob plantio direto quando comparadas à área sob preparo convencional. 
Ngunjiri \& Siemens (1995) avaliaram os efeitos do tráfego de rodas no padrão de crescimento do milho e seu desenvolvimento radicular. Observaram que a densidade de raízes é máxima na linha de plantio e diminui com o aumento da distância entre o ponto de amostragem e o centro da linha de plantio, sendo este comportamento independente do sistema de preparo do solo.

Em uma avaliação da densidade do solo em solos com diferentes texturas sob dois sistemas de preparo do solo, Silva et al. (1997) verificaram a importância relativa da textura, do conteúdo de matéria orgânica e do manejo na densidade do solo. Concluíram que o efeito do preparo do solo na densidade do solo depende da posição relativa à linha de plantio. A interação significativa entre o sistema de preparo e a posição de amostragem demonstrou que a densidade do solo foi significativamente maior no plantio direto do que no preparo convencional na linha, enquanto na entrelinha não observaram diferenças significativas na densidade do solo entre os sistemas de preparo do solo. A densidade do solo foi significativamente maior na entrelinha do que na linha nos dois sistemas de preparo do solo, sendo a diferença mais pronunciada no preparo convencional do que no plantio direto.

A resistência do solo à penetração é um outro atributo do solo que pode limitar o desenvolvimento do sistema radicular (Russel, 1977). A resistência do solo à penetração varia positivamente com a densidade do solo e negativamente com o conteúdo de água do solo (Beltrame et al., 1981; Eavis, 1972; Mirreh \& Ketcheson, 1972). Em solos compactados o aumento da resistência do solo à penetração pode estar associado com um decréscimo na aeração, o que representa um impedimento ao crescimento e funcionamento das raízes (Barley, 1963). Assim como diversos atributos do solo, a resistência do solo à penetração também apresenta grande variabilidade no campo.

Neste sentido, alguns trabalhos foram realizados para detectar a distribuição da resistência do solo à penetração no campo através da análise espectral. Em 1989, Silva et al. analisaram a variabilidade espacial da resistência do solo à penetração de um latossolo e observaram variações sistemáticas da resistência à penetração ao longo do traçado de amostragem, o que confirma a grande variabilidade da resistência no campo 
em função da utilização de diferentes máquinas e implementos agrícolas utilizados no preparo do solo. Domsch (1997) analisou a estrutura do solo através da resistência do solo à penetração, constatando que a variação sistemática da resistência do solo à penetração ao longo das transeções de amostragem refletia os efeitos das operações de cultivo do solo.

A análise espectral tem sido empregada em diversos estudos. Vieira et al. (1987) utilizaram a análise espectral para estudar a altura de plantas de crotalária e concluíram que as variações observadas na altura das plantas estavam relacionadas com os resíduos de adubação aplicada nas linhas de uva cultivada anteriormente. A precipitação e o regime pluviométrico do nordeste do Brasil foram estudados por Reddy (1984) que utilizou a análise espectral para identificar a variação cíclica deste fenômeno. Kachanoski et al. (1985) empregando a análise espectral observaram que a variação espacial da densidade do solo do horizonte A não foi significativa.

Alguns trabalhos já realizados não identificaram se a distribuição da densidade do solo com a posição relativa à linha de plantio é sistemática. A hipótese de que a variação da densidade do solo é influenciada pela posição relativa à linha de plantio, sendo este efeito sistemático e influenciado pelo sistema de preparo do solo orientou o desenvolvimento do presente estudo. 


\section{MATERIAL E MÉTODOS}

O presente estudo foi conduzido na Fazenda Cachoeirinha, situada no município de Guaíra, SP., entre as coordenadas $20^{\circ} 19^{\prime} 13^{\prime \prime}$ de latitude sul e $48^{\circ} 18^{\prime} 03^{\prime \prime}$ de longitude oeste. O clima da região, segundo Köppen, é classificado como subtropical com inverno seco (Cwa). O solo predominante na região é o latossolo roxo que caracteriza-se por ser profundo, bem drenado, com estrutura granular e desenvolvido a partir de intensa intemperização de rochas básicas.

O relevo é suave ondulado com colinas amplas e encostas convexas, uniformes e longas. O uso agrícola é bastante diversificado, predominando as culturas anuais, com destaque para soja, milho, feijão e tomate. O uso e manejo do solo são bastante intensos, principalmente devido à irrigação por aspersão com sistemas de pivô-central.

A granulometria do latossolo roxo presente na área em estudo corresponde a profundidade de 2,5 a 7,5 cm sendo composta por 6,15 e $79 \mathrm{~g} \mathrm{~kg}^{-1}$ de areia, silte e argila, respectivamente. Amostras com estrutura indeformada foram retiradas na área experimental por meio de anéis volumétricos $(4,7 \mathrm{~cm}$ de diâmetro e $5,0 \mathrm{~cm}$ de altura) com auxílio de um amostrador produzido pela empresa Bravifer. As amostras foram coletadas durante a segunda semana do mês de agosto de 1996 em talhões conduzidos no sistema de plantio direto e no sistema de preparo convencional na mesma profundidade em que as amostras de solo para análise granulométrica foram retiradas. Conforme pode ser observado na Figura 1, ao longo de uma transeção perpendicular às linhas de cultivo, foram retiradas 47 amostras de solo na linha da cultura e 47 amostras entre as linha da cultura, totalizando 94 amostras coletadas sequencialmente nas posições linha e entrelinha em cada sistema de preparo do solo. 
A área encontrava-se cultivada com milho (Zea mays L.) cv. Cargil 701, como parte de um sistema de rotação envolvendo as culturas de soja (Glicine max) no verão, milho (Zea mays L.) no inverno e feijão (Phaseolus vulgaris) no verão, sendo a cultura irrigada através de um sistema de pivô-central.

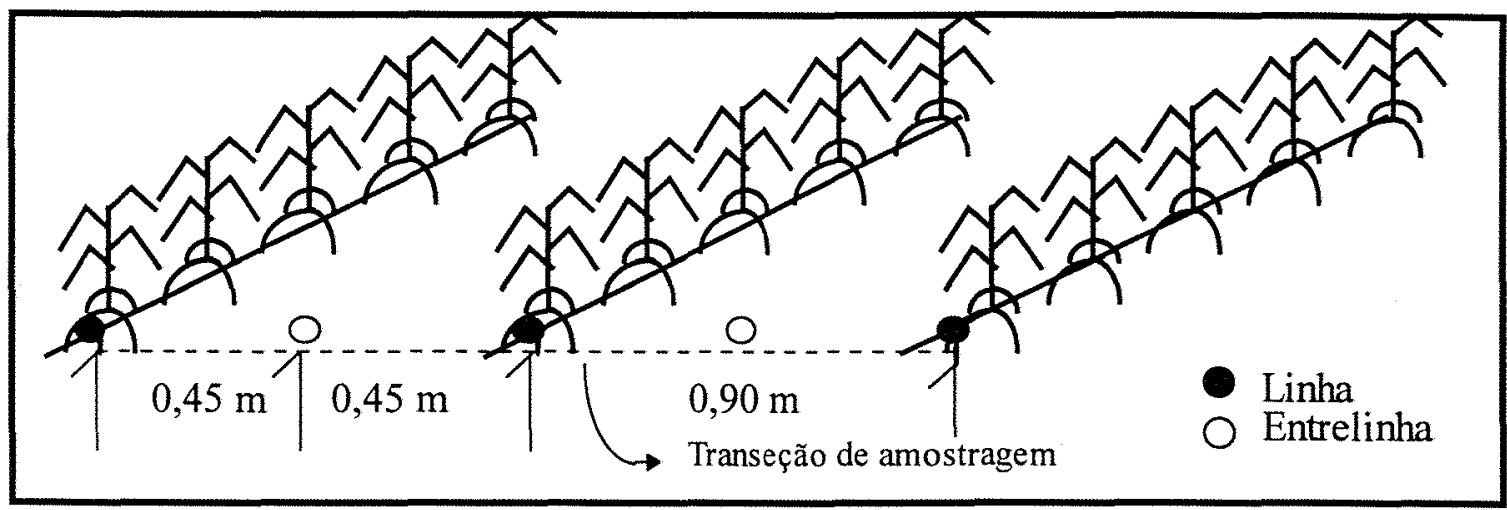

Figura 1 - Esquema de coleta das amostras com estrutura indeformada em um latossolo roxo no município de Guaíra, SP., ao longo de uma transeção perpendicular às linhas de cultivo nas posições linha e entrelinha.

O talhão sob plantio direto estava sendo conduzido pelo quarto ano consecutivo. No talhão cultivado no sistema de preparo convencional, o preparo primário do solo foi feito com grade Rome e o secundário com grade niveladora. O estádio fenológico da cultura na parcela em plantio direto irrigado correspondia ao fim da completa maturação (ponto de colheita) e na parcela em preparo convencional irrigado o estádio fenológico da cultura correspondia ao fim do perfilhamento ou início do florescimento, encontrando-se a cultura com, aproximadamente, 50 dias após germinação. As adubações de plantio e cobertura, bem como a eliminação das plantas indesejáveis foram realizadas conforme recomendações técnicas para a cultura do milho (Fornasieri Filho, 1992 e Lorenzi, 1994).

As amostras com estrutura indeformada foram envoltas em papel alumínio e transportadas para o Laboratório de Física do Solo do Departamento de Ciência do Solo da ESALQ/USP. A densidade do solo foi determinada conforme Blake \& Hartge (1986).

Para identificar o efeito da posição relativa à linha de cultivo na densidade do solo e verificar se este efeito era dependente do sistema de preparo do solo, os valores de densidade do solo medidos foram analisados através do teste $t$, que consiste em um teste de médias. Para isto, foi utilizado procedimentos descritos pelo SAS Institute (1991). 
A análise espectral foi utilizada para identificar se a variação da densidade do solo ocorria de forma sistemática em relação à posição de amostragem, nos dois sistemas de preparo do solo. A análise espectral é uma ferramenta estatística que possibilita identificar a concentração da variância dos dados em determinadas freqüências e assim reconhecer uma possivel periodicidade das variáveis analisadas, sendo melhor descrita em termos da análise harmônica de Fourier. Uma variável medida ao longo de uma distância finita em intervalos igualmente espaçados, pode ser representada por uma série ortogonal finita de Fourier,

$$
Z_{j}=\sum_{K=1}^{N / 2}\left[A_{k} \operatorname{sen}(2 \pi j K / L)+B_{k} \cos (2 \pi j K / L)\right]+A_{0}
$$

onde $Z_{\mathrm{j}}=$ observação até a posição $\mathrm{j}$ na transeção, $\mathrm{j}=1,2, \ldots, \mathrm{N} / 2 ; \mathrm{L}=$ período máximo igual ao comprimento da transeção; $\mathrm{K}=$ número harmônico igual aos ciclos completados no comprimento da transeção; $A_{k}, B_{k}=$ coeficientes da série de Fourier e $A_{0}$ = valor médio de $\mathrm{Z}$.

Os coeficientes da série de Fourier podem ser calculados diretamente por

$$
\begin{aligned}
& A_{k}=(2 / N) \sum_{j=1}^{N} Z_{j} \operatorname{sen}(2 \pi \mathrm{Kj} / L) \\
& B_{k}=(2 / N) \sum_{j=1}^{N} Z_{j} \cos (2 \pi K j / L)
\end{aligned}
$$

O primeiro par harmônico $(\mathrm{K}=1)$ seno e coseno tem uma frequência cíclica igual a $\mathrm{L}^{-1}$ (período igual ao comprimento da transeção) o qual é chamado de frequência cíclica fundamental. $O$ último par harmônico $(K=N / 2)$ seno e coseno tem uma frequência cíclica igual a $\mathrm{N} / 2 \mathrm{~L}$ (período igual ao dobro do intervalo de amostragem) a qual é chamada de frequência Nyquist (Brillinger, 1981).

Assim a frequência Nyquist e a frequência cíclica fundamental determinam as freqüências máximas e mínimas que podem estar distanciadas e são determinadas 
diretamente pelo intervalo de amostragem e pelo comprimento da transeção. A variância $\left(V_{k}\right)$ do termo $\mathrm{K}$ harmônico é dado por (Panofsky \& Brier, 1963),

$$
\mathrm{V}_{\mathrm{k}}=\left(\mathrm{A}_{\mathrm{k}}{ }^{2}+\mathrm{B}_{\mathrm{k}}{ }^{2}\right) / 2
$$

Como os harmônicos de Fourier são ortogonais, cada frequência separada contribui com uma proporção individual da variância total da variável observada. Um gráfico da $V_{k}$ versus a frequência do termo $K$ harmônico é chamado de periodograma (Brillinger, 1981; Jenkins \& Watts, 1968; Panofsky \& Brier, 1963). 


\section{RESULTADOS E DISCUSSÃO}

\subsection{Análise da densidade do solo}

Os momentos estatísticos da densidade do solo para os sistemas avaliados são apresentados na Tabela 1. Os parâmetros são indicativos da variabilidade espacial dos dados. A maior amplitude dos valores de densidade do solo foi obtida na linha do plantio direto seguido pela entrelinha do preparo convencional.

Os valores do coeficiente de variação, em torno de $5 \%$, bem como a constatação da distribuição normal ( $W ; p>0,05)$ dos valores de densidade estão de acordo com os resultados obtidos por Nielsen et al. (1973) e Silva et al. (1997).

Tabela 1. Parâmetros da análise estatística dos dados de densidade do solo para os dois sistemas de preparo do solo.

\begin{tabular}{|lcccc|}
\hline \multicolumn{1}{|c}{ Parâmetros* } & PD - L & PD - EL & PC - L & PC - EL \\
\hline N & 47 & 47 & 47 & 47 \\
Média & 1,13 & 1,19 & 1,09 & 1,16 \\
Desvio Padrão & 0,0632 & 0,0593 & 0,0561 & 0,0736 \\
Mínimo & 0,95 & 1,07 & 0,93 & 1,02 \\
Máximo & 1,27 & 1,32 & 1,22 & 1,33 \\
C.V. & 5,612 & 5,001 & 5,147 & 5,348 \\
W & 0,9718 & 0,9737 & 0,9814 & 0,9784 \\
p $>$ W & 0,4590 & 0,5099 & 0,7935 & 0,6892 \\
\hline
\end{tabular}

*Para $\mathrm{p}<\mathrm{t}=0,0001 ; \mathrm{PD}=$ plantio direto; $\mathrm{PC}=$ preparo convencional $\mathrm{L}=$ linha; $\mathrm{EL}=$ entrelinha; $\mathrm{W}=$ estatística de Shapiro-Wilk; $\mathrm{p}>\mathrm{W}=$ probabilidade dos dados apresentarem distribuição normal. Os resultados apresentam distribuição normal pois $\mathrm{p}>$ W é maior que 0,05 .

A densidade média nos dois sistemas de preparo do solo, independente da posição, é apresentada na Figura 2. Foi observada uma diferença significativa $(t=3,01$ e 
$\mathrm{p}<\mathrm{t}=0,0030$ ) entre os sistemas de preparo com valores maiores da densidade do solo no sistema de plantio direto.

O mesmo comportamento foi observado por Gantzer \& Blake (1978), Pidgeion \& Soane (1977), Silva et al. (1997) e Vieira e Muzilli (1984) que trabalharam com solos do grupo Oxissol na profundidade compreendida entre 0 a $15 \mathrm{~cm}$.

1.25

1.20

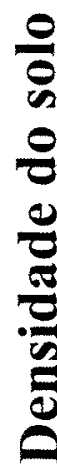

\begin{tabular}{l}
0 \\
0 \\
8 \\
8 \\
0 \\
$\frac{0}{0}$ \\
$\frac{0}{0}$ \\
$\frac{0}{0}$ \\
\hline
\end{tabular}

1.05

1.15

1.10

1.00

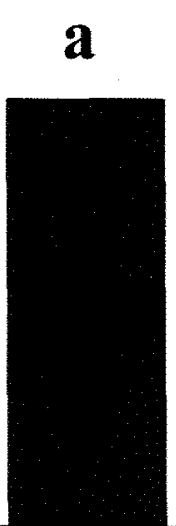

PC b

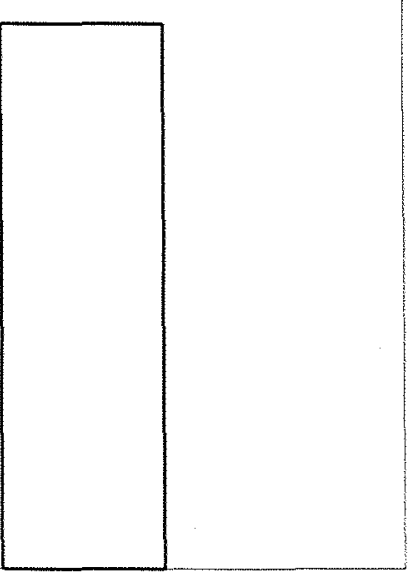

PD

Figura 2 - Densidade do solo $\left(\mathrm{Mg} \mathrm{m}^{-3}\right)$ nos sistemas de preparo convencional (PC) e plantio direto (PD).

Trabalhos demonstraram que a maior densidade do solo no plantio direto é limitada aos primeiros $0,15 \mathrm{~m}$ de profundidade em áreas onde este sistema de preparo está implantado há relativamente pouco tempo (Pidgeon \& Soane, 1977; Unger, 1996), o que corresponde às condições experimentais do presente trabalho.

Resultados diferentes foram obtidos por Albuquerque et al. (1995), Hill \& Cruse (1985) e Merten \& Mielniczuk (1991), que não observaram diferenças significativas, 
com respeito a densidade do solo, entre o sistema de plantio direto e o preparo convencional.

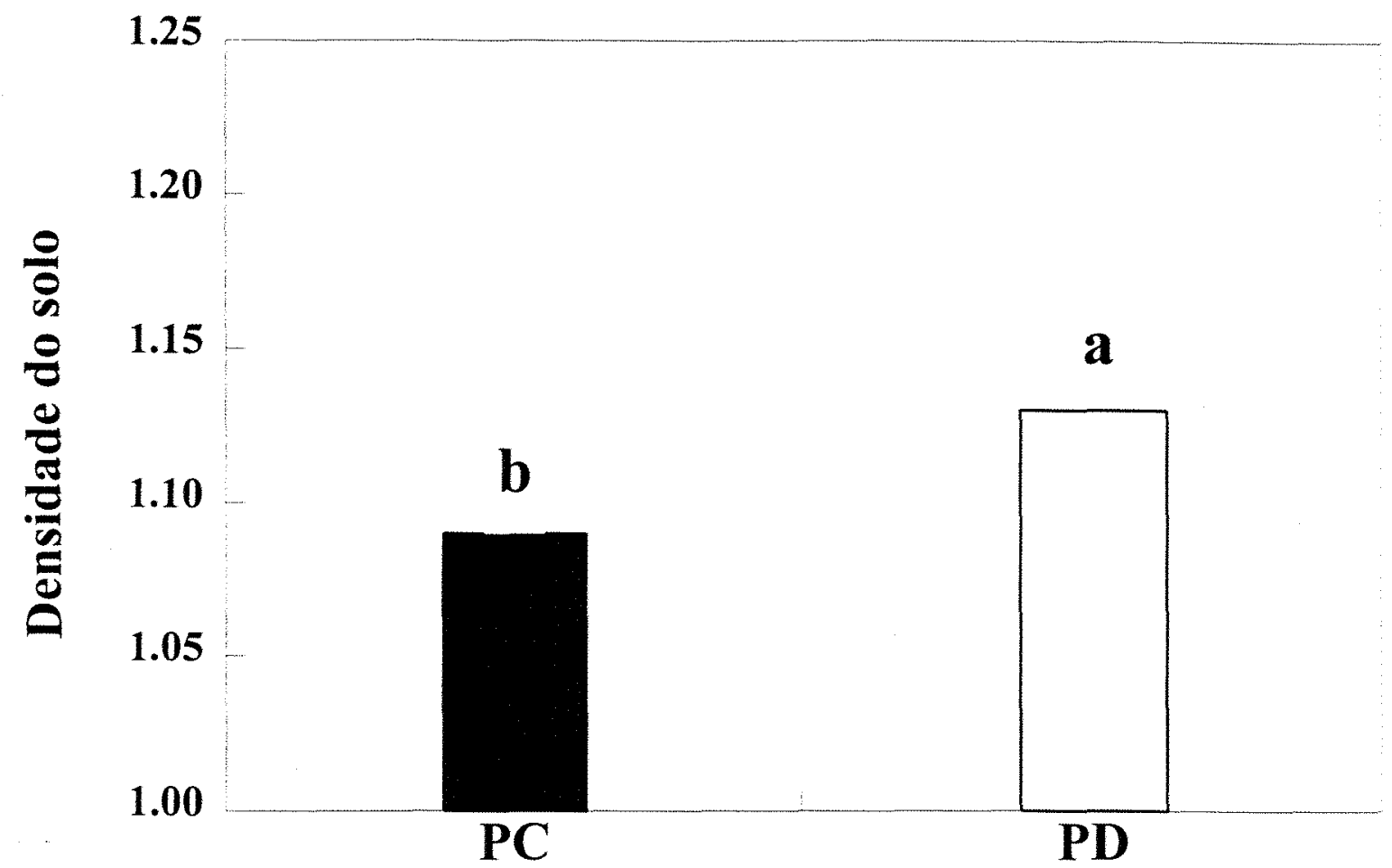

Figura 3 - Densidade do solo $\left(\mathrm{Mg} \mathrm{m}^{-3}\right)$ na posição linha nos sistemas de preparo convencional (PC) e plantio direto (PD).

A diferença na densidade do solo entre os sistemas de preparo foi dependente da posição relativa à linha de plantio. Comparando-se a densidade do solo dos dois sistemas de preparo do solo com relação ao efeito da linha, observou-se (Figura 3) que a densidade do solo na linha no plantio direto foi maior do que no preparo convencional $(\mathrm{t}=2,97$ e $\mathrm{p}<\mathrm{t}=0,0038)$. Por outro lado, a densidade do solo no plantio direto não diferiu significativamente $(\mathrm{t}=1,87$ e $\mathrm{p}<\mathrm{t}=0,07)$ da densidade do solo no preparo convencional quando utilizou-se a densidade medida na entrelinha (Figura 4). Esse mesmo comportamento foi observado por Silva et al. (1997).

Uma possível explicação para a maior densidade do solo observada na linha no plantio direto é que neste sistema o solo não sofre revolvimento da camada superficial. 
O solo é somente mobilizado na linha de semeadura e no momento do plantio. Quando uma nova semeadura é realizada, um novo sulco é aberto na área correspondente à entrelinha da cultura anterior. A ação de raízes e organismos na zona de enraizamento na linha é a mesma, tanto no plantio direto como no preparo convencional.

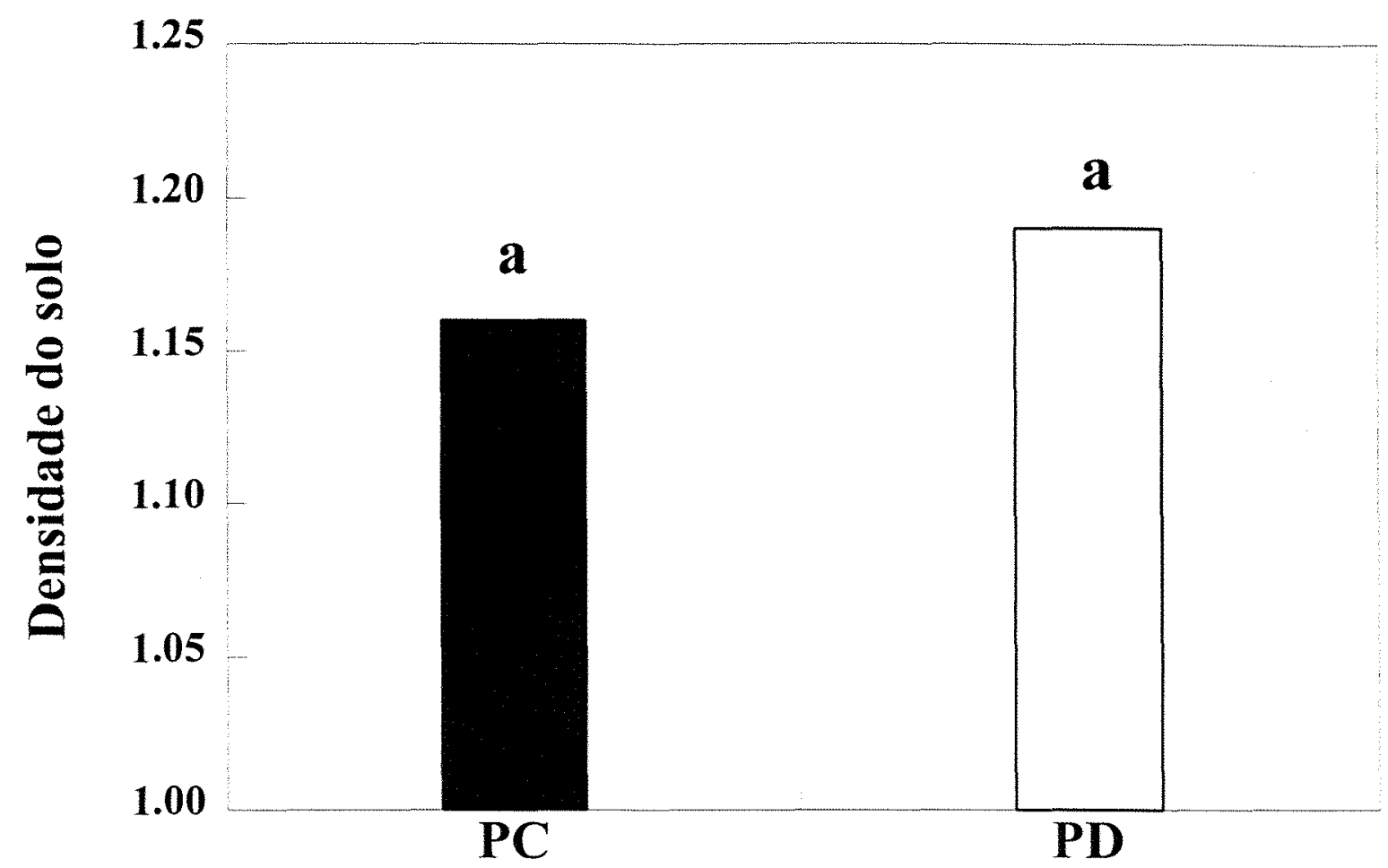

Figura 4 - Densidade do solo $\left(\mathrm{Mg} \mathrm{m}^{-3}\right)$ na posição entrelinha nos sistemas de preparo convencional (PC) e plantio direto (PD).

No preparo convencional a mobilização da camada arável do solo em toda a área promove a fragmentação dos agregados, reduzindo a densidade inicial do solo por ocasião do preparo. Com isto, a densidade do solo na linha no plantio direto poderia apresentar-se maior do que no preparo convencional para a profundidade amostrada.

A densidade do solo variou significativamente em relação a posição nos dois sistemas de preparo. A Figura 5 apresenta a densidade média do solo no sistema de plantio direto para a linha e a entrelinha. A densidade do solo na entrelinha foi 
significativamente maior do que na linha $(t=4,68$ e $p<t=0,0001)$. O efeito da posição relativa à linha de plantio no sistema de preparo convencional pode ser observado na Figura 6.

Os resultados foram similares aos obtidos no plantio direto. A densidade média do solo foi maior na entrelinha do que na linha $(t=5,18$ e $p<t=0,0001)$. Esse comportamento também foi observado por Silva et al. (1997) que trabalharam com amostras com estrutura indeformada coletadas na profundidade de 0 a $5 \mathrm{~cm}$ estando o solo submetido aos sistemas de preparo convencional e plantio direto.

1.25

1.20

$\mathbf{a}$

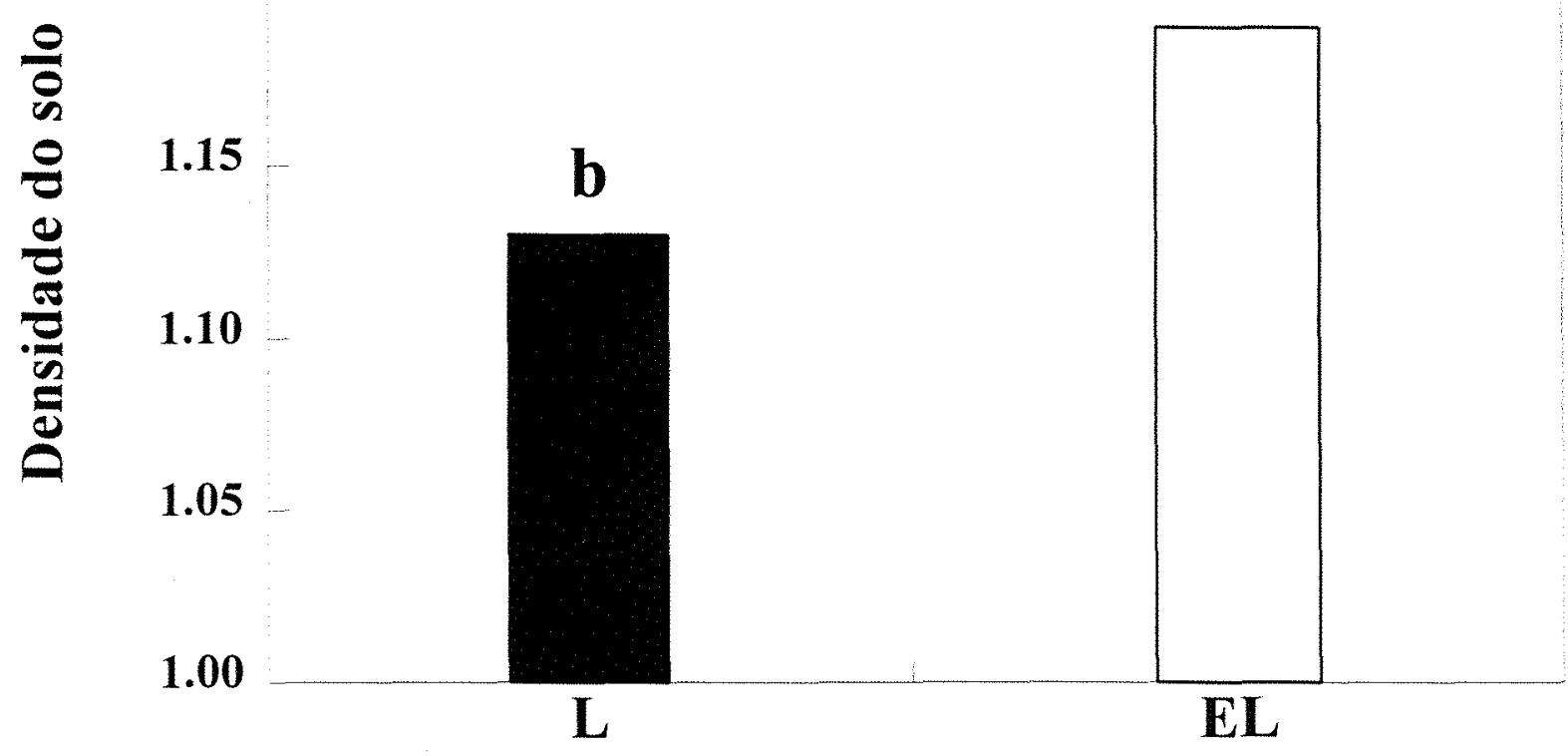

Figura 5 - Efeito da posição relativa à linha de plantio na densidade do solo $\left(\mathrm{Mg} \mathrm{m}^{-3}\right)$ no sistema de plantio direto em um latossolo roxo localizado no município de Guaíra, SP., nas posições linha (L) e entrelinha (EL).

No preparo convencional a camada superficial é mobilizada por ocasião do preparo do solo para o plantio mas, após a semeadura, as entrelinhas da cultura são expostas ao tráfego de máquinas e implementos devido às operações necessárias aos tratos culturais e fitossanitários, podendo resultar em maior densidade do solo na 
entrelinha quando comparado à linha neste sistema de preparo. Além disto a consolidação natural que ocorre no solo após a mobilização da camada superficial também contribui com este efeito.

Já no plantio direto apesar da camada superficial não ser mobilizada por ocasião do preparo do solo para o plantio, um sulco é aberto no momento da semeadura, reduzindo a densidade do solo na linha, comparativamente a região das entrelinhas então formadas.

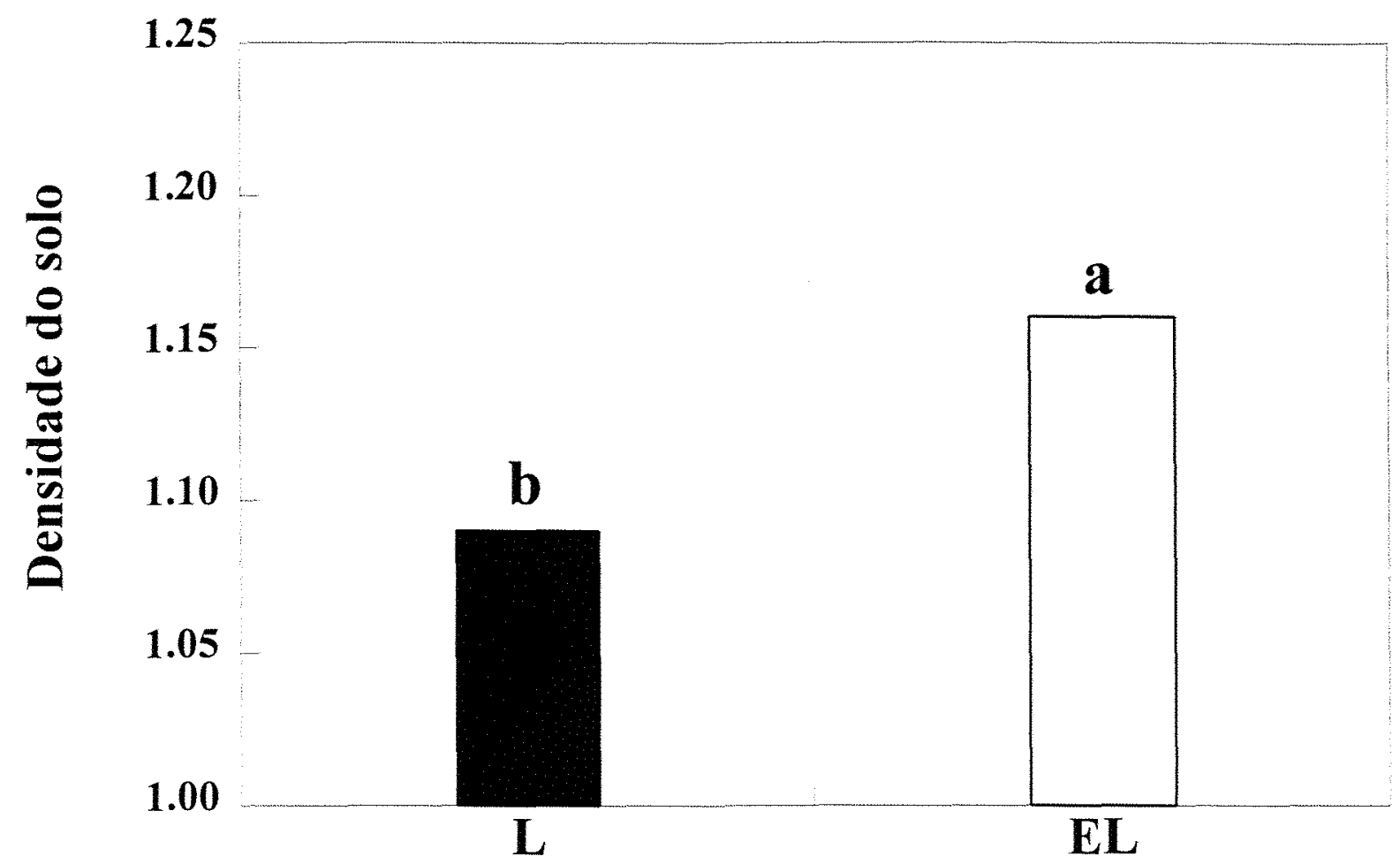

Figura 6 - Efeito da posição relativa à linha de plantio na densidade do solo $\left(\mathrm{Mg} \mathrm{m}^{-3}\right)$ no sistema de preparo convencional em um latossolo roxo localizado no município de Guaíra, SP., nas posições linha (L) e entrelinha (EL).

A maior densidade do solo observada na linha tanto no sistema de plantio direto como no sistema de preparo convencional pode estar associada à ação das raízes e dos microrganismos do solo.

Cassel (1982) concluiu que amostragens aleatórias para quantificar a densidade do solo não permitem isolar o efeito das posições linha e entrelinha. A Figura 7 mostra 
a densidade do solo ao longo da transeção no plantio direto e do preparo convencional, através da qual pode-se observar a grande variabilidade da densidade do solo nos sistemas de preparo.

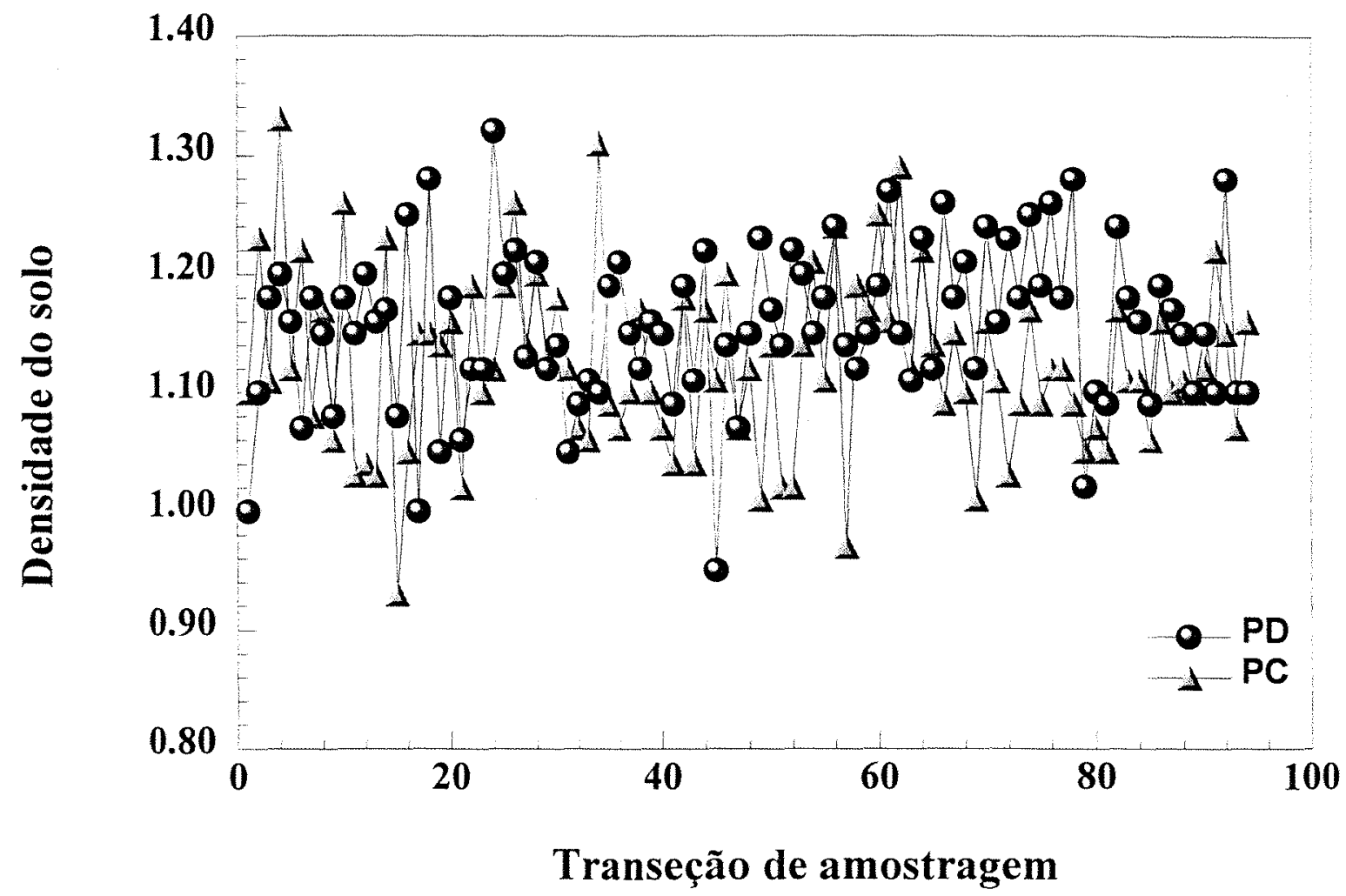

Figura 7 - Densidade do solo $\left(\mathrm{Mg} \mathrm{m}^{-3}\right)$ ao longo da transeção de amostragem no sistema de plantio direto $(\mathrm{PD})$ e preparo convencional $(\mathrm{PC})$.

Ao longo da transeção perpendicular às linhas de plantio (Figura 7) o aumento dos valores pontuais da densidade do solo podem estar restringindo ou limitando o desenvolvimento do sistema radicular das plantas de milho em diferentes posições em função da relação da densidade do solo com outras propriedades físicas do solo que influenciam diretamente o crescimento de raízes como a aeração e a resistência mecânica que o solo oferece à penetração de raízes (Letey, 1985).

É importante verificar se a maior densidade do solo observada na entrelinha das culturas nos dois sistemas de preparo ocorre de maneira sistemática ou aleatória. Para 
isto, a análise espectral foi aplicada. A análise espectral permitiu verificar a periodicidade de variáveis utilizando-se a série de Fourier como uma ferramenta estatística. O efeito sistemático da densidade do solo com a posição de amostragem pode ser identificado através dos picos das variâncias apresentados em um gráfico que representa a densidade espectral, sendo as variâncias plotadas contra a freqüência da densidade do solo ao longo da transeção de amostragem.

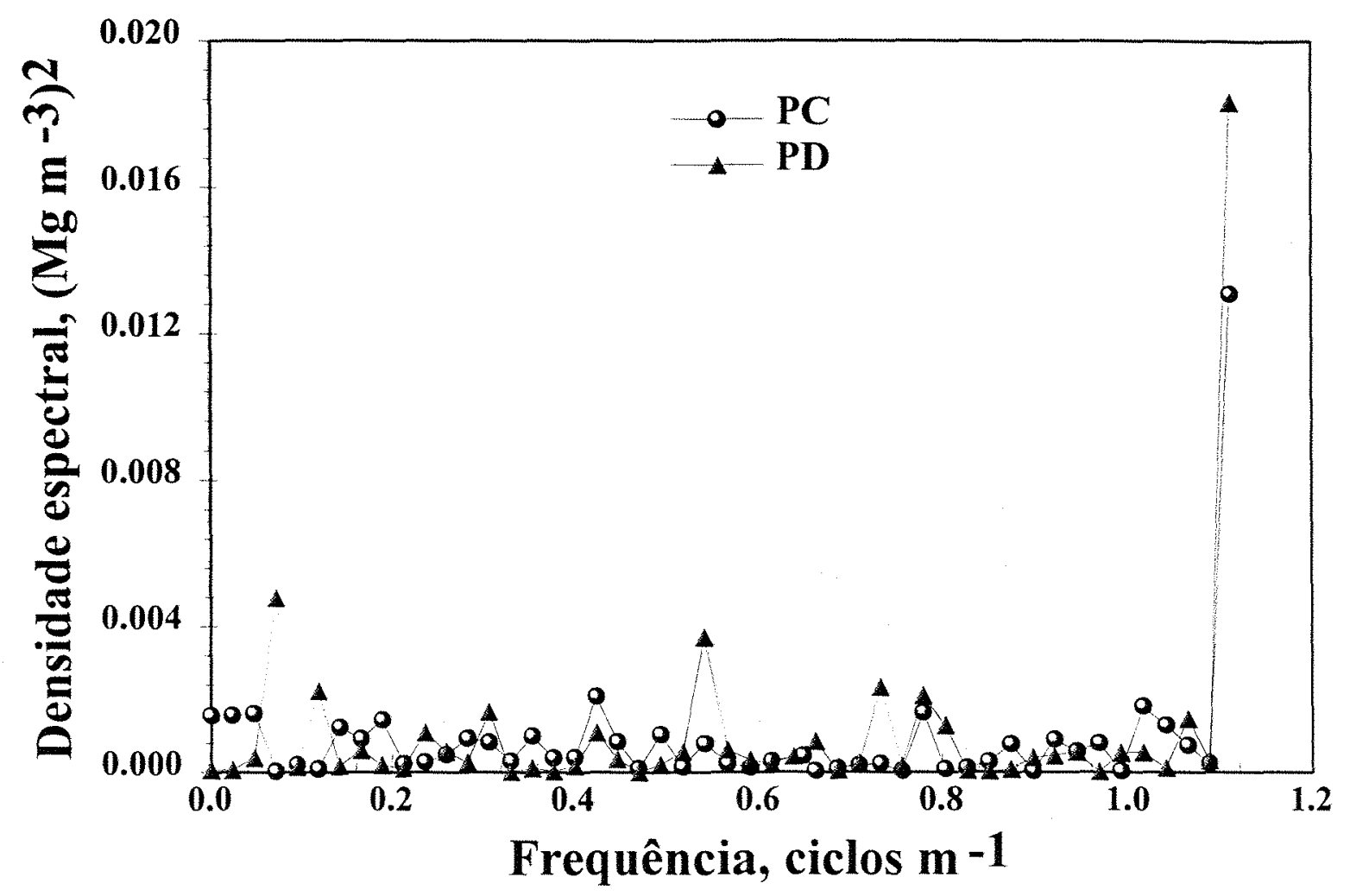

Figura 8 - Densidade espectral $\left(\left(\mathrm{Mg} \mathrm{m}^{-3}\right)^{2}\right)$ da densidade do solo nos sistemas de plantio direto (PD) e preparo convencional (PC).

Os resultados obtidos com a análise espectral são apresentados na Figura 8, onde destaca-se o pico localizado na frequência 1,11 ciclos $\mathrm{m}^{-1}$, correspondente a distância de $0,45 \mathrm{~m}$ e equivalente ao espaçamento entre as posições linha e entrelinha na transeção de amostragem. Este resultado permite afirmar que a maior proporção da variância ocorreu 
entre as posições de amostragem o que confirma a variação sistemática da densidade do solo em relação a posição.

Pode-se também observar (Figura 8) a menor variância da densidade do solo no sistema de plantio direto comparativamente ao sistema de preparo convencional. Estas diferenças com relação a posição relativa à linha de plantio entre os sistemas de preparo do solo indicam que alguns cuidados devem ser considerados no planejamento da amostragem do solo, pois a variação da densidade do solo ocorre de forma sistemática com a posição.

\subsection{A distribuição da densidade do solo e outros parâmetros físicos}

Uma vez observado a grande variabilidade da densidade do solo no campo para a profundidade estudada e estando a densidade do solo relacionada com diversos outros parâmetros do solo, algumas figuras foram confeccionadas de forma a ilustrar a influência da densidade do solo na aeração e na resistência do solo.

As Figuras 9 e 10 foram elaboradas a partir das densidades do solo medidas e representam a porosidade de aeração do solo ao longo da transeção de amostragem para os dois sistemas de preparo, para a umidade equivalente a tensão de 0,033 MPa.

No plantio direto a porosidade de aeração do solo foi maior na linha do que na entrelinha ao longo de quase toda a transeção de amostragem. Pode-se observar, na Figura 9 , que na $9^{\mathrm{a}}$ posição (indicada por uma seta no gráfico) a porosidade de aeração foi de $19,6 \%$ na linha e de $9,1 \%$ na entrelinha.

Considerando-se como um valor limitante para o crescimento de plantas a porosidade de aeração de 10\% (Dexter, 1988; Grable \& Siemer, 1968), o valor citado para a entrelinha sugere uma possível restrição ao desenvolvimento radicular devido à inadequada aeração.

Esta condição também foi observada para outros pontos de amostragem ao longo da transeção estudada no plantio direto, indicando que as condições físicas limitantes ao 
crescimento radicular ocorrem com mais freqüência na porção entrelinha do que na linha da cultura.

Estas condições limitantes ao desenvolvimento radicular podem ser resultantes da ausência de revolvimento da camada superficial, propiciando a formação de maior quantidade de microporos nas entrelinhas da cultura, associado ao tráfego de máquinas neste sistema de preparo e ao acúmulo de resíduos culturais sobre a superfície do solo, que reduzem a perda de umidade do solo mantendo maior quantidade de água armazenada no espaço poroso do solo. Este conjunto de fatores implicam na deficiência de aeração do solo nas entrelinhas da lavoura.

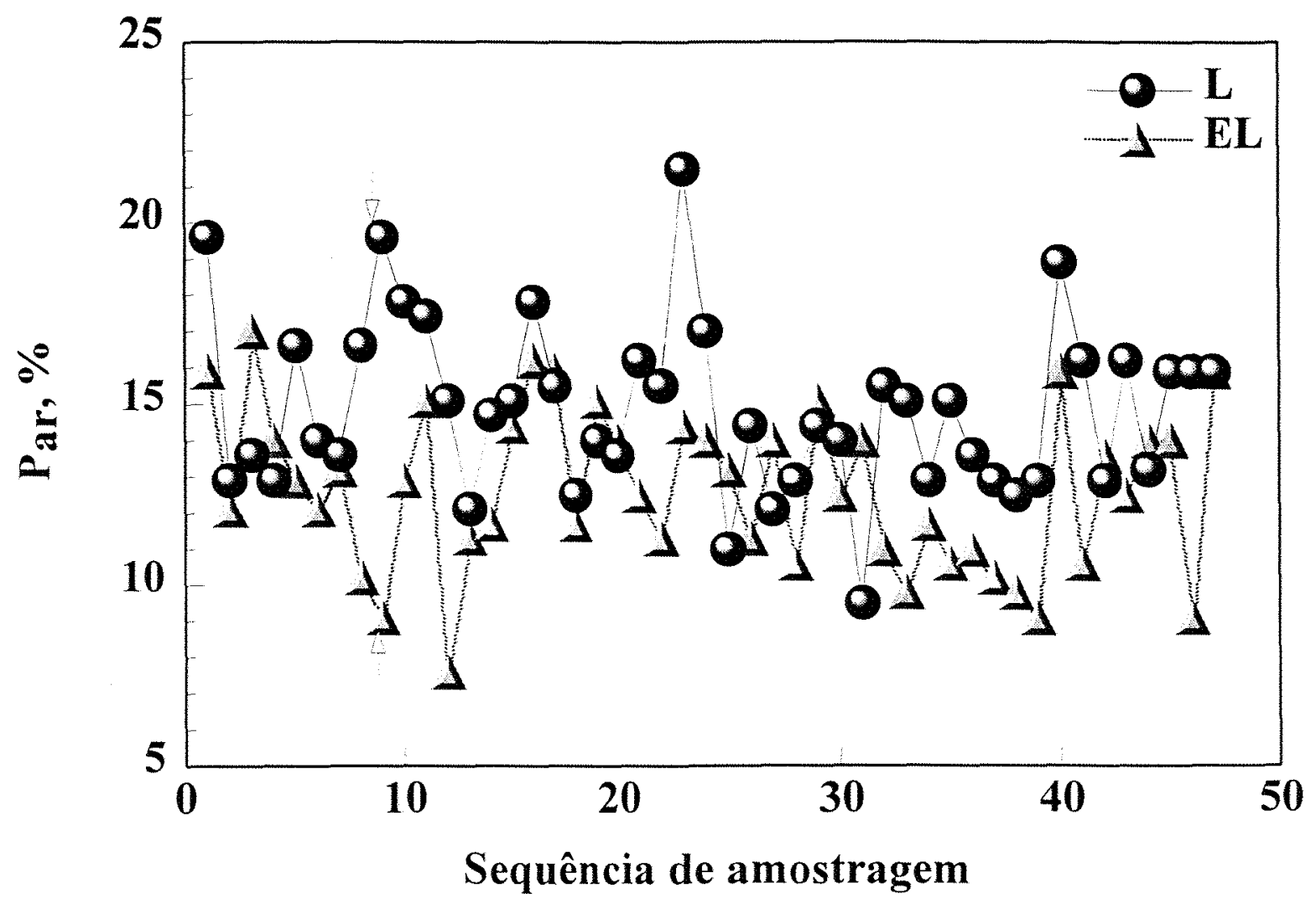

Figura 9 - Porosidade de aeração $\left(\mathrm{P}_{\mathrm{ar}}, \%\right)$ na posição linha $(\mathrm{L})$ e entrelinha $(\mathrm{EL})$ no sistema de plantio direto ao longo de uma sequência de amostragem perpendicular às linhas de plantio em um latossolo roxo cultivado com milho para umidade do solo equivalente a tensão de $0,033 \mathrm{MPa}$. 
Os resultados da variação da porosidade de aeração ao longo da transeção no preparo convencional (Figura 10) indicaram que a porosidade de aeração, de maneira geral, foi menor na entrelinha, embora em pontos específicos da transeção a porosidade de aeração seja maior na linha de plantio (Ex. pontos 16 e 36 na transeção estudada).

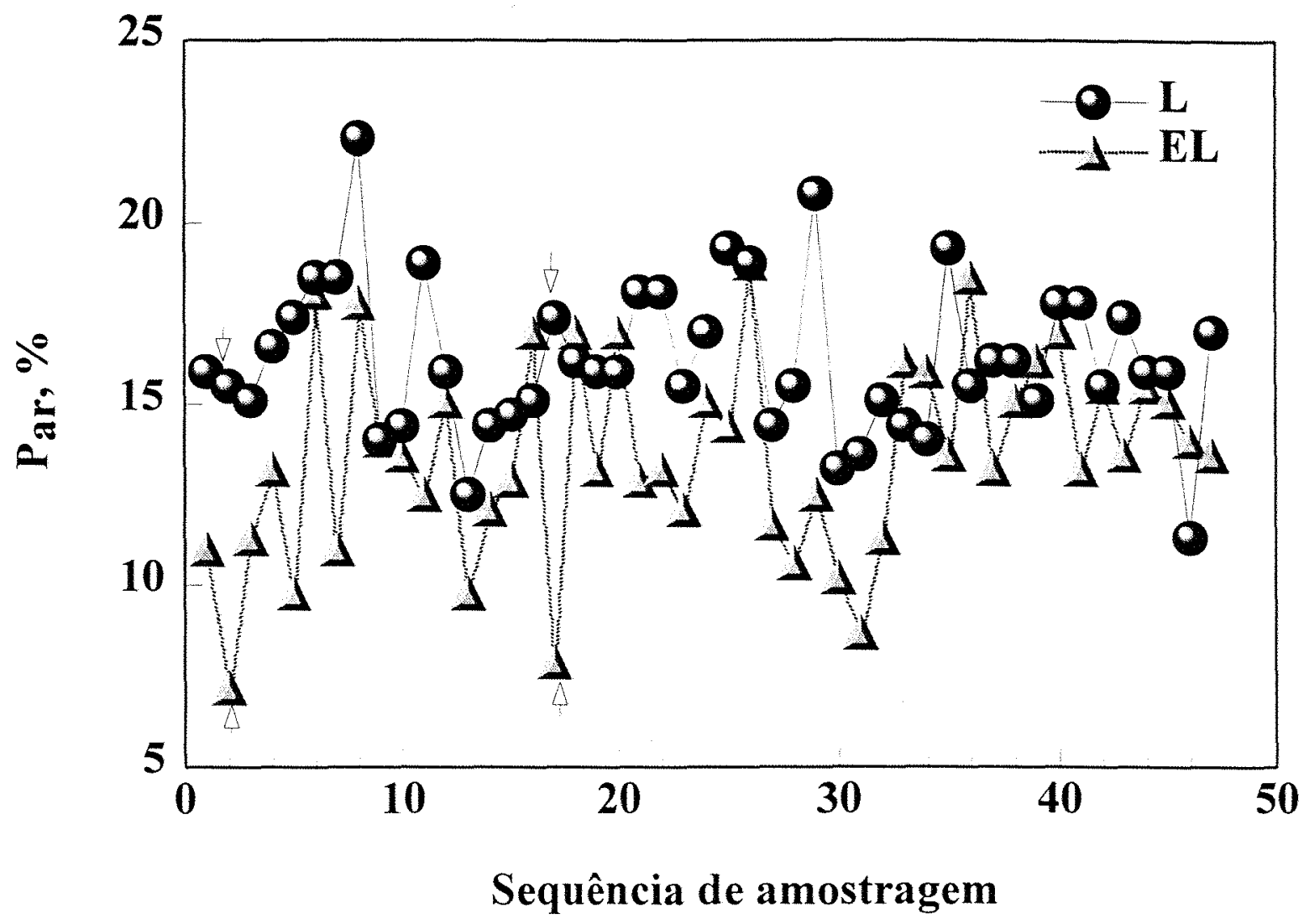

Figura 10 - Porosidade de aeração ( $\left.\mathrm{P}_{\mathrm{ar}}, \%\right)$ na linha $(\mathrm{L})$ e entrelinha (EL) no sistema de preparo convencional ao longo de uma seqüência de amostragem perpendicular às linhas de plantio em um latossolo roxo cultivado com milho para umidade do solo equivalente a tensão de $0,033 \mathrm{MPa}$.

As maiores amplitudes observadas neste sistema de preparo em função das posições analisadas estão presentes no $2^{\circ}$ e $17^{\circ}$ ponto da transeção. Nestas posições de amostragem a entrelinha apresentou 7,2\% e 7,9\% de porosidade de aeração, respectivamente. No plantio direto a freqüência com que a porosidade de aeração ficou abaixo de $10 \%$ e correspondeu a $2,1 \%$ e $12,8 \%$ das amostras nas posições linha e 
entrelinha respectivamente, enquanto que no preparo convencional $10,6 \%$ dos pontos apresentaram porosidade de aeração abaixo de $10 \%$ na entrelinha.

A resistência do solo à penetração é um outro parâmetro do solo que pode limitar o desenvolvimento do sistema radicular (Russel, 1977). A resistência a penetração varia com a densidade e umidade do solo (Beltrame et al., 1981). Conhecendo-se a influência da densidade do solo na resistência à penetração, diversos modelos tem sido ajustados para explicar a variação da resistência à penetração em função da densidade do solo e da umidade do solo (Busscher et al., 1990; Silva et al., 1994).

Na mesma área utilizada no presente estudo, Correchel et al. (1997) ajustaram um modelo proposto por Busscher et al. (1990) para estimar a resistência à penetração considerando a densidade do solo e a umidade do solo conforme descrito abaixo:

$$
\begin{aligned}
& \text { PD: } R P=0.0222 . D s^{8.2080} \cdot \theta^{-2.6908} \\
& \text { PC: } R P=0.0194 . \mathrm{Ds}^{8.2080} \cdot \theta^{-2.6908}
\end{aligned}
$$

onde, $\mathrm{PD}=$ plantio direto, $\mathrm{PC}=$ preparo convencional, $\mathrm{RP}=$ resistência do solo à penetração $(\mathrm{MPa}), \theta=$ umidade do solo $\left(\mathrm{cm}^{3} \mathrm{~cm}^{-3}\right), \mathrm{Ds}=$ densidade do solo $\left(\mathrm{Mg} \mathrm{m}^{-3}\right)$.

Com o objetivo de demonstrar os efeitos da densidade do solo sobre a variação da resistência à penetração nos sistemas de preparo e nas posições linha e entrelinha, estimou-se a resistência à penetração para um valor de umidade correspondente a 0,7 MPa. Estes dados estão apresentados nas Figuras 11 e 12.

No sistema de plantio direto a resistência à penetração na entrelinha apresentou valores acima de $2 \mathrm{MPa}$, valor este considerado limitante ao desenvolvimento radicular (Allmaras \& Longsdon, 1990). Comparando-se a linha com a entrelinha o $9^{\circ}$ ponto, por exemplo, alcançou o valor de 3,91 MPa na entrelinha enquanto na mesma posição a resistência à penetração na linha foi de $0,52 \mathrm{MPa}$. O mesmo ocorreu na $46^{\circ}$ posição, onde a linha apresentou resistência à penetração de 1,13 $\mathrm{MPa}$ contra 3,91 $\mathrm{MPa}$ na entrelinha.

A resistência à penetração apresenta relação inversa à taxa de elongação das raízes (Barley, 1972; Eavis, 1972; Mirreh \& Ketcheson, 1973; Russell, 1977). Assim, os 
valores que estão em destaque no texto representam os pontos da transeção de amostragem onde verificou-se, para a tensão equivalente à $0,7 \mathrm{MPa}$, valores de resistência do solo superiores à $2 \mathrm{MPa}$ que pontualmente podem estar restringindo ou limitando o desenvolvimento do sistema radicular nas posições acima citadas.

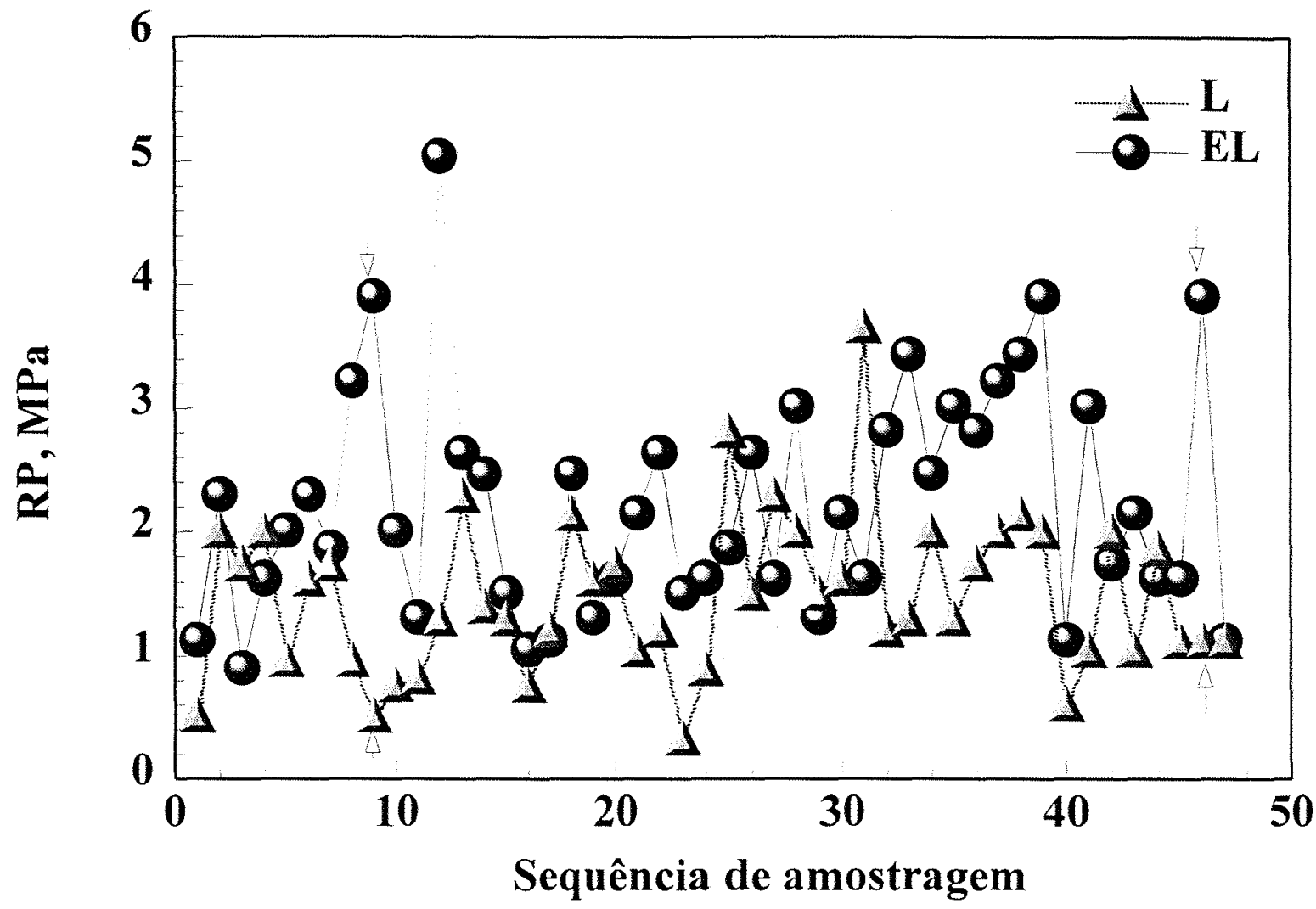

Figura 11 - Resistência do solo à penetração $(R P)$ na posição linha $(L)$ e entrelinha $(E L)$ no sistema de plantio direto ao longo de uma sequência de amostragem perpendicular às linhas de plantio em um latossolo roxo cultivado com milho para umidade do solo equivalente a tensão de $0,70 \mathrm{MPa}$.

No sistema de plantio direto cerca de $27,7 \%$ e $55,3 \%$ das amostras apresentaram resistência à penetração maior do que $2 \mathrm{MPa}$ nas posições linha e entrelinha, respectivamente, enquanto no preparo convencional a freqüência foi bem menor, apresentada por $2,1 \%$ dos pontos na linha e $29,8 \%$ na entrelinha. 


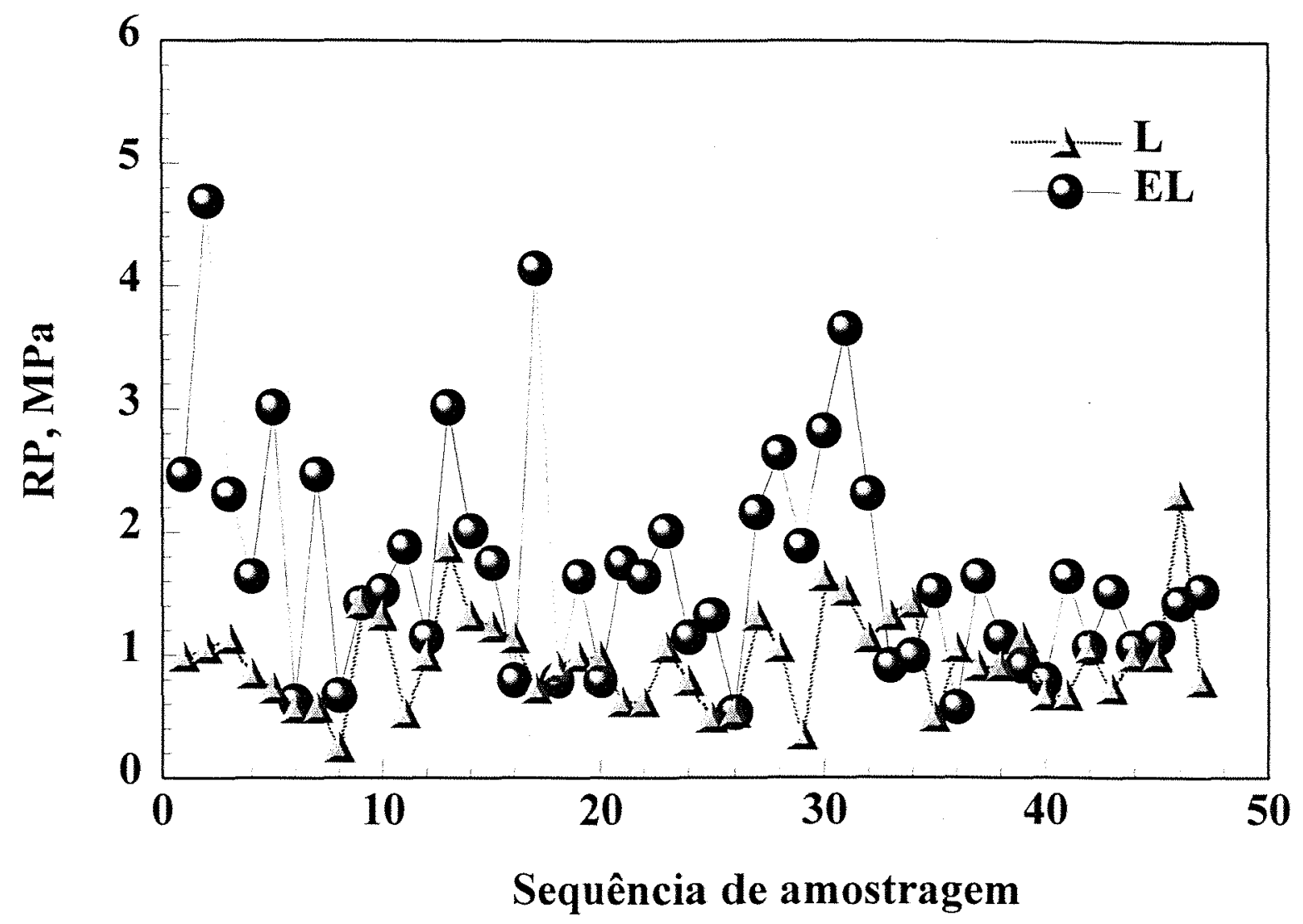

Figura 12 - Resistência do solo à penetração (RP) na posição linha (L) e entrelinha (EL) no sistema de preparo convencional ao longo de uma sequência de amostragem perpendicular às linhas de plantio em um latossolo roxo cultivado com milho para umidade do solo equivalente a tensão de 0,70 $\mathrm{MPa}$. 


\section{CONCLUSÕES}

Diante dos resultados obtidos pode-se concluir que

(i) A distribuição da densidade do solo no campo é influenciada pela posição relativa à linha de cultivo;

(ii) A influência da posição relativa à linha de cultivo na variação da densidade do solo não depende do sistema de preparo do solo;

(iii) A densidade do solo varia de forma sistemática com a posição linha e entrelinha nos dois sistemas de preparo do solo. 


\section{REFERÊNCIAS BIBLIOGRÁFICAS}

ALBUQUERQUE, J.A.; REINERT, D.J.; FIORIN, J.E.; RUEDELL, J.; PETRERE, C.; FONTINELLI, F. Rotação de culturas e sistemas de manejo do solo: efeito sobre a forma estrutural do solo ao final de sete anos. Revista brasileira de Ciência do Solo, v. 19, p.115-119, jan./abr. 1995.

ALLMARAS, R.R.; LONGSDON, S.D. Soil structural influences on the root zone and rhizosphere. In: Rhizosphere dynamics. ed. AAAS, p.8-54. 1990.

BARLEY, K.P. Influence of soil strengh on growth of roots. Soil Science, v.96, p.175$180,1963$.

BARLEY, K.P. The effects of mechanical stress on the growth of roots. Journal of Experimental Botany, v. 37, n.13, p.95-110, 1972.

BAUDER, J.W.; RANDALL, G.W.; SCHULER, R.T. Effects of tillage with controlled wheel traffic on soil properties and root growth of corn. Journal of Soil and Water Conservation, p. 382-385, July/Aug. 1985.

BELTRAME, L.F.S.; GONDIM, L.A.P.; TAYLOR, J.C. Estrutura e compactação na permeabilidade de solos do RGS. Revista Brasileira de Ciência do Solo, v.3, n.5, p.145-149, set./dez. 1981. 
BLAKE, G.R.; HARTGE, K.H. Bulk density. In: KLUTE,A. (Ed.) Methods of soil analisys: physical and mineralogical methods. Madison: ASA, SSSA, 1986. p.363-375.

BODMAN, G.B.; CONSTANTIN, G.K. Influence of particle size distribution in soil compaction. Hilgardia, v.36, n.15, p. 567-591, Oct. 1965.

BRILLINGER, D.R. Time series, data analysis and theory. Holden-Day Ins. San Francisco, CA. 1981.

BUSSCHER, W.J. Adjustmente of flat-tipped penetrometer resistance data to a commom water content. Transactions of the ASAE, v.3, n.2, p.519-524, 1990.

CASSEL, D.K. Tillage effects on soil bulk density and mechanical impedance. In: UNGER, P.; Jr., van DOREN, D.M. (Ed.) Predicting tillage effects on soil physical properties and process. Madison: ASA, 1982. p.45-68. (ASA. Special Publications, 44)

CINTRA, F.L.D.; MIELNICZUK, J.; SCOPEL, I. Caracterização do impedimento mecânico em um latossolo roxo do Rio Grande do Sul. Revista Brasileira de Ciência do Solo, v.7, n.3, p.323-327, set./dez. 1983.

CORRECHEL, V.; SILVA, A.P. da; TORMENA, A.C.; SANCHES, A.C. Resistência de um latossolo roxo ao penetrômetro em dois sistemas de preparo do solo. (compact disc). In: CONGRESSO BRASILEIRO DE CIÊNCIA DO SOLO, 26, Rio de Janeiro, 1997. Informação de solo na globalização do conhecimento sobre o uso das terras: resumos. Rio de Janeiro: SBCS, 1997. 
DEXTER, A.R. Prediction of soil structures produced by tillage. Journal of Terramechanics, v.16, p.117-127. 1979.

DEXTER, A.R. Advances in characterization of soil structure. Soil \& Tillage Research, v.11, p.199-238, 1988.

DOMSCH, H. On-site diagnosis of soil structure for site specific management. In: PRECISION AGRICULTURE, 1, Warwick University Conference Centre, UK, 1997. Spatial variability in soil and crop. Warwick: BIOS Scientific Publishers Limited, 1997. p. $95-102$.

EAVIS, B.W. Soil physical condition affecting seedlling root growth. I.Mechanical impedance, aeration and moisture availability and moisture levels in a sandy loam soil. Plant and Soil, v. 36, p. 613-622, 1972.

ERBACH, D.C. Measurement of soil bulk density and moisture. Transactions of the ASAE, v.30, n.4, p.921-931, July/Aug. 1987.

FAUSEY, N.R.; DYLLA, A.S. Effects of wheel traffic along one side of corn and soybeans rows. Soil \& Tillage Research, v.4, p.147-154, 1984.

FORNASIERI FILHO, D. A cultura do milho. Jaboticabal: FUNEP, 1992. 273p.

GANTZER, C.J.; BLAKE, G.R. Physical characteristics of de Sueur clay loam soil following no-till and conventional tillage. Agronomy Journal, v.70, p.853-857, Sept./Oct. 1978. 
GERIK, T.J.; MORRISON, J.E. JR.; CHICHESTER, F.W. Effects of controlled-traffic on soil physical properties and crop rooting. Agronomy Journal, v.79, p.434-438, 1987.

GRABLE, A.R.; SIEMER, E.G. Effects of bulk density, aggregate size and soil water suction on oxygen diffusion, redox potentials and elongation of corn roots. Soil Science Society of America Proceedings, v.32, p.180-186, 1968.

HILL, R.L.; CRUSE, R.M. Tillage effects on bulk density and soil strengh of two Mollisols. Soil Science Society of America Journal, v.49, p.1270-1273, 1985.

HILL, R.L. Long-term conventional and no-tillage effects on selected soil physical properties. Soil Science Society of America Journal, v.54, p.161-166, 1990.

JENKINS, G.M.; WATTS, D.G. Spectral analysis and its applications. San Francisco: Holden Day Inc. Publi., 1968. 525p.

JONES, C.A. Effect of soil texture on critical bulk densities for root growth. Soil Science Society of America Journal, v.47, p.1208-1211, 1983.

KACHANOSKI, R.G.; ROLSTON, D.E.; JONG, E. DE. Spatial and spectral relationships of soil properties and microtophotography: I.Density and thickness of A horizon. Soil Science Society of America Journal, v.49, p.804-812, 1985.

KASPAR, T.C.; BROWN, H.J.; KASSMEYER, E.M. Corn root distribution as affected by tillage, wheel traffic, and fertilizer placement. Soil Science Society of America Journal, v.55, p.1390-1394, 1991. 
KASPAR, T.C.; LOGSDON, S.D.; PRIEKSAT, M.A. Traffic pattern and tillage system effects on corn root and shoot growth. Agronomy Journal, v.87, p.1046-1051, Nov./Dec. 1995.

LETEY, J. Relationship between soil physical properties and crop production. Advances in Soil Science, v.1, p.277-294, 1985.

LORENZI, H. Manual de identificação e controle de plantas daninhas: plantio direto e convencional. Nova Odessa: Plantarum, 1994. 229 p.

MACHADO, J.A.; BRUM, A.C.R. Efeito de sistemas de cultivo em algumas propriedades fisicas do solo. Revista Brasileira de Ciência do Solo, v.2, n.3, p. 8184, set./dez. 1978.

MAIRINQUE, L.A.; JONES, C.A. Bulk density of soil in relation to soil physical and chemical properties. Soil Science Society of America Journal, v..55, p.476-480, Mar./Apr. 1991.

MERTEN, G.H.; MIELNICZUK, J. Distribuição do sistema radicular e dos nutrientes em latossolo roxo sob dois sistemas de preparo do solo. Revista Brasileira de Ciência do Solo, v.15, n.3, p.369-374, set./dez. 1991.

MIELKE, L.N.; DORAN, J.W.; RICHARDS, K.A. Physical environment near the surface of plowed and no-tilled soils. Soil \& Tillage Research, v.7, p.355-366, 1986.

MIRREH, H.F.; KETCHESON, J.W. Influence of soil bulk density and matric pressure on soil resistance to penetration. Canadian Journal of Soil Science, v. 52, p. 477483, 1972. 
MIRREH, H.F.; KETCHESON, J.W. Influence of soil water matric potential and resistance to penetration on corn root elongation. Canadian Journal of Soil Science, v. 53, p. $383-388,1973$.

NGUNJIRI, G.M.; SIEMENS, J.C. Wheel traffic effects on corn growth. American Society of Agricultura Engineers. Transactions of the ASAE, v.38, n.3, p.691-699, 1995.

NIELSEN, D.R.; BIGGAR, J.W.; ERH, K.T. Spatial variability of soil properties. Hilgardia, v.42, n.7, p.215-259, 1973.

PANOFSKY, H.A.; BRIER, G.W. Some applications of statistics to meteorology. The Pennsylvania State Univ., University Park. p.127-161. 1963.

PEDROTTI, A. Compactação do solo: um problema oculto. Lavoura Arrozeira, v.48, n.418, p.18-21, jan./fev. 1995.

PIDGEON, J.D.; SOANE, B.D. Effects of tillage and direct drilling on soil properties during the growing season in a long-term barley mono-culture system. Journal of Agricultural of Science, v.88, p.431-442, 1977.

REDDY, S.J. Climatic fluctuations and homogenization of northeast Brazil using precipitation data. Pesquisa Agropecuária Brasileira, v.19, n.5, p.529-543, maio. 1984.

RUSSEL, S. Mechanical impedance of root growth. In: RUSSELL, S. (Ed.) Plant root systems: their function and interaction with the soil. 1977. p.169-192. 
SAS INSTITUTE. SAS/STAT procedure guide for personal computers: Version 5. Cary, 1991. 552p.

SCOTT, H.D.; WOOD, L.S. Impact of crop production on the physical status of a typic albaqualf. Soil Science Society of America Journal, v.53, p.1819-1825, 1989.

SIDIRAS, N.; VIEIRA, S.R.; ROTH, C.H. Determinação de algumas características físicas de um latossolo roxo distrófico sob plantio direto e preparo convencional. Revista Brasileira de Ciência do Solo, v.8, n.3, p.265-268, set./dez. 1984.

SILVA, A.P. da; KAY, B.D.; PERFECT, E. Characterization of the least limiting water range of soils. Soil Science Society of America Journal, n.58, p. 1775-1781, 1994.

SILVA, A.P. da; KAY, B.D.; PERFECT, E. Management versus inherent soil properties effects on bulk density and relative compaction. Soil \& Tillage Research, v.44, p.81-93, 1997.

SILVA, A.P. da; LIBARDI, P.L.; VIEIRA, S.R. Variabilidade espacial da resistência à penetração de um latossolo vermelho-escuro ao longo de uma transeção. Revista Brasileira de Ciência do Solo, v.13, p.1-5, 1989.

SOANE, B.D.; BLACKWELL, P.S.; DICKSON, J.W.; PAINTER, D.J. Compaction by agricultural vehicles: a review. I. Soil and whell characteristics. Soil \& Tillage Research, v.1, p. 207-237, 1981.

UNGER, P.W. Soil bulk density, penetration resistance, and hydraulic conductivity under controlled traffic conditions. Soil \& Tillage Research, v.37, p.67-75, 1996. 
VIEIRA, M.C.; MUZILLI, O. Características físicas de um latossolo vermelho-amarelo sob diferentes sistemas de manejo. Pesquisa Agropecuária Brasileira, v.7, n.19, p.873-882, jul. 1984 .

VIEIRA, S.R.; MARIA, I.C. de; CASTRO, O.M. de; DECHEN, S.C.F.; LOMBARDI NETO, F. Uitilização da análise de fourier no estudo do efeito residual da adubação em uva na crotalária. Revista Brasileira de Ciência do Solo, v.11, n.1, p.7-10, jan./abr. 1987. 
APÊNDICE 
Apêndice 1. Densidade do solo (Ds, $\mathrm{Mg} \mathrm{m}^{-3}$ ) nas posições linha (L) e entrelinha (EL) ao longo da transeção perpendicular às linhas de cultivo no sistema de plantio direto (PD) e no sistema de preparo convencional (PC), conforme a seqüência de amostragem realizada.

\begin{tabular}{|c|c|c|c|}
\hline Seqüência & Posição & $\mathbf{P D}$ & $\mathbf{P C}$ \\
\hline 1 & $\mathrm{~L}$ & 1,00 & 1,10 \\
\hline 2 & EL & 1,10 & 1,23 \\
\hline 3 & $\mathrm{~L}$ & 1,18 & 1,11 \\
\hline 4 & EL & 1,20 & 1,33 \\
\hline 5 & $\mathrm{~L}$ & 1,16 & 1,12 \\
\hline 6 & EL & 1,07 & 1,22 \\
\hline 7 & L & 1,18 & 1,08 \\
\hline 8 & EL & 1,15 & 1,17 \\
\hline 9 & L & 1,08 & 1,06 \\
\hline 10 & EL & 1,18 & 1,26 \\
\hline 11 & $\mathrm{~L}$ & 1,15 & 1,03 \\
\hline 12 & EL & 1,20 & 1,04 \\
\hline 13 & $L$ & 1,16 & 1,03 \\
\hline 14 & $\mathrm{EL}$ & 1,17 & 1,23 \\
\hline 15 & $\mathrm{~L}$ & 1,08 & 0,93 \\
\hline 16 & EL & 1,25 & 1,05 \\
\hline 17 & L & 1,00 & 1,15 \\
\hline 18 & EL & 1,28 & 1,15 \\
\hline 19 & $\mathrm{~L}$ & 1,05 & 1,14 \\
\hline 20 & $\mathrm{EL}$ & 1,18 & 1,16 \\
\hline 21 & L & 1,06 & 1,02 \\
\hline 22 & EL & 1,12 & 1,19 \\
\hline 23 & L & 1,12 & 1,10 \\
\hline 24 & EL & 1,32 & 1,12 \\
\hline 25 & $\mathrm{~L}$ & 1,20 & 1,19 \\
\hline 26 & EL & 1,22 & 1,26 \\
\hline 27 & $\mathrm{~L}$ & 1,13 & 1,14 \\
\hline 28 & $\mathrm{EL}$ & 1,21 & 1,20 \\
\hline 29 & L & 1,12 & 1,13 \\
\hline 30 & $\mathrm{EL}$ & 1,14 & 1,18 \\
\hline 31 & $\mathrm{~L}$ & 1,05 & 1,12 \\
\hline 32 & EL & 1,09 & 1,07 \\
\hline 33 & L & 1,11 & 1,06 \\
\hline 34 & EL & 1,10 & 1,31 \\
\hline 35 & $\mathrm{~L}$ & 1,19 & 1,09 \\
\hline 36 & EL & 1,21 & 1,07 \\
\hline 37 & $\mathrm{~L}$ & 1,15 & 1,10 \\
\hline
\end{tabular}




\begin{tabular}{|c|c|c|c|}
\hline Seqüência & Posição & $\mathbf{P D}$ & PC \\
\hline 38 & $\overline{E L}$ & 1,12 & 1,17 \\
\hline 39 & $\mathrm{~L}$ & 1,16 & 1,10 \\
\hline 40 & EL & 1,15 & 1,07 \\
\hline 41 & L & 1,09 & 1,04 \\
\hline 42 & EL & 1,19 & 1,18 \\
\hline 43 & $\mathrm{~L}$ & 1,11 & 1,04 \\
\hline 44 & EL & 1,22 & 1,17 \\
\hline 45 & $\mathrm{~L}$ & 0,95 & 1,11 \\
\hline 46 & EL & 1,14 & 1,20 \\
\hline 47 & $\mathrm{~L}$ & 1,07 & 1,07 \\
\hline 48 & EL & 1,15 & 1,12 \\
\hline 49 & $\mathrm{~L}$ & 1,23 & 1,01 \\
\hline 50 & $\mathrm{EL}$ & 1,17 & 1,14 \\
\hline 51 & L & 1,14 & 1,02 \\
\hline 52 & EL & 1,22 & 1,02 \\
\hline 53 & $\mathrm{~L}$ & 1,20 & 1,14 \\
\hline 54 & $\mathrm{EL}$ & 1,15 & 1,21 \\
\hline 55 & $L$ & 1,18 & 1,11 \\
\hline 56 & EL & 1,24 & 1,24 \\
\hline 57 & L & 1,14 & 0,97 \\
\hline 58 & EL & 1,12 & 1,19 \\
\hline 59 & $\mathrm{~L}$ & 1,15 & 1,17 \\
\hline 60 & EL & 1,19 & 1,25 \\
\hline 61 & $\mathrm{~L}$ & 1,27 & 1,16 \\
\hline 62 & EL & 1,15 & 1,29 \\
\hline 63 & $\mathrm{~L}$ & 1,11 & 1,12 \\
\hline 64 & EL & 1,23 & 1,22 \\
\hline 65 & $\mathrm{~L}$ & 1,12 & 1,14 \\
\hline 66 & EL & 1,26 & 1,09 \\
\hline 67 & $\mathrm{~L}$ & 1,18 & 1,15 \\
\hline 68 & $\mathrm{EL}$ & 1,21 & 1,10 \\
\hline 69 & $\mathrm{~L}$ & 1,12 & 1,01 \\
\hline 70 & EL & 1,24 & 1,16 \\
\hline 71 & $\mathrm{~L}$ & 1,16 & 1,11 \\
\hline 72 & EL & 1,23 & 1,03 \\
\hline 73 & $\mathrm{~L}$ & 1,18 & 1,09 \\
\hline 74 & EL & 1,25 & 1,17 \\
\hline 75 & $\mathrm{~L}$ & 1,19 & 1,09 \\
\hline 76 & $\mathrm{EL}$ & 1,26 & 1,12 \\
\hline 77 & $\mathrm{~L}$ & 1,18 & 1,12 \\
\hline 78 & EL & 1,28 & 1,09 \\
\hline 79 & L & 1,02 & 1,05 \\
\hline
\end{tabular}




\begin{tabular}{|cccc|}
\hline Seqüência & Posição & PD & PC \\
\hline 80 & EL & 1,10 & 1,07 \\
81 & L & 1,09 & 1,05 \\
82 & EL & 1,24 & 1,17 \\
83 & L & 1,18 & 1,11 \\
84 & EL & 1,16 & 1,11 \\
85 & L & 1,09 & 1,06 \\
86 & EL & 1,19 & 1,16 \\
87 & L & 1,17 & 1,10 \\
88 & EL & 1,15 & 1,11 \\
89 & L & 1,10 & 1,10 \\
90 & EL & 1,15 & 1,12 \\
91 & L & 1,10 & 1,22 \\
92 & EL & 1,28 & 1,15 \\
93 & L & 1,10 & 1,07 \\
94 & EL & 1,10 & 1,16 \\
\hline
\end{tabular}


Apêndice 2. Densidade espectral da densidade do solo para os sistemas de plantio direto (PD) e preparo convencional (PC), ao longo da transeção de amostragem.

\begin{tabular}{|c|c|c|}
\hline \multirow[b]{2}{*}{ Frequência, ciclos $\mathbf{m}^{-1}$} & \multicolumn{2}{|c|}{ Espectro } \\
\hline & PD & $\mathbf{P C}$ \\
\hline 0,0000 & 0,001554 & 0,000064 \\
\hline 0,0236 & 0,001554 & 0,000064 \\
\hline 0,0472 & 0,001600 & 0,000388 \\
\hline 0,0709 & 0,000022 & 0,004785 \\
\hline 0,0945 & 0,000192 & 0,000145 \\
\hline 0,1181 & 0,000082 & 0,002228 \\
\hline 0,1417 & 0,001205 & 0,000157 \\
\hline 0,1653 & 0,000908 & 0,000598 \\
\hline 0,1889 & 0,001417 & 0,000187 \\
\hline 0,2126 & 0,000221 & 0,000098 \\
\hline 0,2362 & 0,000272 & 0,001087 \\
\hline 0,2598 & 0,000473 & 0,000562 \\
\hline 0,2834 & 0,000926 & 0,000268 \\
\hline 0,3070 & 0,000813 & 0,001647 \\
\hline 0,3306 & 0,000294 & 0,000013 \\
\hline 0,3543 & 0,000977 & 0,000104 \\
\hline 0,3779 & 0,000388 & 0,000024 \\
\hline 0,4015 & 0,000395 & 0,000166 \\
\hline 0,4251 & 0,002072 & 0,001087 \\
\hline 0,4487 & 0,000830 & 0,000361 \\
\hline 0,4723 & 0,000092 & 0,000006 \\
\hline 0,4960 & 0,001017 & 0,000191 \\
\hline 0,5196 & 0,000140 & 0,000557 \\
\hline 0,5432 & 0,000780 & 0,003700 \\
\hline 0,5668 & 0,000230 & 0,000604 \\
\hline 0,5904 & 0,000113 & 0,000330 \\
\hline 0,6140 & 0,000293 & 0,000213 \\
\hline 0,6483 & 0,000446 & 0,000437 \\
\hline 0,6613 & 0,000031 & 0,000845 \\
\hline 0,6849 & 0,000099 & 0,000048 \\
\hline 0,7085 & 0,000182 & 0,000250 \\
\hline 0,7321 & 0,000227 & 0,002332 \\
\hline 0,7557 & 0,000022 & 0,000156 \\
\hline 0,7794 & 0,001628 & 0,002100 \\
\hline 0,8030 & 0,000074 & 0,001280 \\
\hline 0,8266 & 0,000110 & 0,000042 \\
\hline 0,8502 & 0,000285 & 0,000031 \\
\hline
\end{tabular}




\begin{tabular}{|c|c|c|}
\hline & \multicolumn{2}{|c|}{ Espectro } \\
\hline Frequência, ciclos $\mathbf{m}^{-1}$ & PD & $\mathbf{P C}$ \\
\hline 0,8738 & 0,000764 & 0,000078 \\
\hline 0,8974 & 0,000016 & 0,000387 \\
\hline 0,9211 & 0,000883 & 0,000447 \\
\hline 0,9447 & 0,000567 & 0,000556 \\
\hline 0,9683 & 0,000785 & 0,000010 \\
\hline 0,9919 & 0,000030 & 0,000522 \\
\hline 1,0155 & 0,001793 & 0,000525 \\
\hline 1,0392 & 0,001278 & 0,000108 \\
\hline 1,0628 & 0,000733 & 0,001467 \\
\hline 1,0864 & 0,000244 & 0,000329 \\
\hline 1,1100 & 0,013085 & 0,018327 \\
\hline
\end{tabular}

